\title{
Tissue differentiation and bone regeneration in an osteotomized mandible: a computational analysis of the latency period
}

\author{
A. Boccaccio ${ }^{1,2}$, P.J. Prendergast ${ }^{2}$, C. Pappalettere ${ }^{1}$, D.J. Kelly ${ }^{2}$ \\ ${ }^{I}$ Dipartimento di Ingegneria Meccanica e Gestionale, Politecnico di Bari, 70126, Bari, Italy \\ ${ }^{2}$ Trinity Centre for Bioengineering, Department of Mechanical and Manufacturing Engineering, Trinity College \\ Dublin, Ireland.
}

$\underline{\text { Address correspondence to: }}$

Dr. Daniel Kelly

Mailing Address:

Centre for Bioengineering,

Department of Mechanical Engineering,

Trinity College Dublin,

Dublin 2,

Ireland.

Contact Information:

Tel: +353-1-6083947 (Daniel Kelly);

Fax: +353-1-6795554 (Daniel Kelly);

Email: kellyd9@tcd.ie (Daniel Kelly); 


\section{Abstract}

Mandibular symphyseal distraction osteogenesis is a common clinical procedure to modify the geometrical shape of the mandible for correcting problems of dental overcrowding and arch shrinkage. In spite of consolidated clinical use, questions remain concerning the optimal latency period and the influence of mastication loading on osteogenesis within the callus prior to the first distraction of the mandible. This work utilized a mechano-regulation model to assess bone regeneration within the callus of an osteotomized mandible. A 3D model of the mandible was reconstructed from CT scan data and meshed using poroelastic finite elements. The stimulus regulating tissue differentiation within the callus was hypothesized to be a function of the strain and fluid flow computed by the finite element model. This model was then used to analyse tissue differentiation during a fifteen day latency period, defined as the time between the day of the osteotomy and the day when the first distraction is given to the device. The following predictions are made: (i) the mastication forces generated during the latency period support osteogenesis in certain regions of the callus, and that during the latency period the percentage of progenitor cells differentiating into osteoblasts increases; (ii) reducing the mastication load by $70 \%$ during the latency period increases the number of progenitor cells differentiating into osteoblasts; (iii) the stiffness of new tissue increases at a slower rate on the side of bone callus next to the occlusion of the mandibular ramus which could cause asymmetries in the bone tissue formation with respect to the middle sagittal plane. Although the model predicts that the mastication loading generates such asymmetries, their effects on the spatial distribution of callus mechanical properties are insignificant for typical latency periods used clinically. It is also predicted that a latency period of longer than a week will increase the risk of premature bone union across the callus.

Keywords: Mechanobiology; Mandibular distraction osteogenesis; Orthodontic devices; Tissue differentiation; Finite element modelling. 


\section{Introduction}

The problems of posterior buccal nonocclusion (a skeletal deficiency where occlusion cannot occur on both sides of the posterior region of the oral cavity), mandibular anterior crowding and narrowed arches are usually solved in growing patients by tooth extraction or expansion techniques. However expansion of the anterior dentoalveolar structures is often unstable and tends to relapse towards the original dimension $[22,40]$. Mandibular transversal distraction osteogenesis may solve transverse mandibular deficiency problems. With this clinical procedure the mandibular geometry is definitively changed. Distraction osteogenesis facilitates osteo-synthesis via distraction of the existing bone tissue. Bone elongation begins when the callus formed after the osteotomy is slowly distracted. Tensile stresses acting on the bone tissue are thought to stimulate bone re-growth in the direction of applied forces [14]. Mandibular transversal distraction osteogenesis is therefore based on the "law of tension-stress" proposed by Ilizarov [26], which states that progressive tensioning of vital tissues will create stresses that induce and maintain growth and proliferation of the tissue. This hypothesis is supported by the results of Kaspar et al. [29], who reported greater mitogenic activity in cells from a distracted bone callus compared to a normal bone callus.

Utilization of distraction osteogenesis in the cranio-maxillo-facial region is justified by the development and progressive improvements of dento-facial traction, cranio-facial osteotomies and skeletal fixation methodologies. Several clinical studies report the promising results obtained from patients treated with mandibular distraction osteogenesis $[16,19,20,51]$. During a typical mandibular distraction osteogenesis procedure, the mandible is first osteotomized and then instrumented by applying a distraction orthodontic device. After a latency period of seven to ten days [13], the distractor is progressively opened by giving the same daily expansion for between 5 and 10 days. The expansion process is then terminated and the level of aperture is kept constant in order to facilitate the formation of new bone tissue in the osteotomized region. The latency period is critical for successful mandibular distraction osteogenesis. If the latency period is too short, a weak and insufficient callus will form, and without a good callus not enough new bone may form and 
complications may arise such as fibrous union, non-union, tooth loss and periodontal defects [13]. On the other hand, too long a latency period may substantially increase the risk of premature bone union [27], which can hinder the subsequent expansion process.

A number of studies have used the finite element $(\mathrm{FE})$ method to investigate the mechanics of mandibular distraction osteogenesis [5, 7, 8, 11, 32]. Loboa et al. [35] used a FE approach to study tissue differentiation at different stages of mandibular distraction osteogenesis in a rat model. By comparing the predicted levels of stresses and strains to histological findings, they showed that tensile strain up $13 \%$ in the bone callus corresponded to regions of new bone formation and regions of periosteal hydrostatic pressure with magnitude less than $17 \mathrm{kPa}$ corresponded to locations of cartilage formation. However, to date, no clear mechano-biological explanation has been given for the influence of (i) the length of the latency period, and (ii) the magnitude of mastication loading, on osteogenesis within the callus prior to mandibular distraction ostengenesis.

Comparing patterns of differentiation during tissue repair to predictions of the mechanical environment within the mesenchymal tissue has led to the development of a number of hypotheses for mechano-regulated tissue differentiation. Pauwels [42], who was the first to propose such a hypothesis, suggested that the distortional shear stress is a specific stimulus for the development of collagenous fibres, and that hydrostatic compressive stress is a specific stimulus for cartilage formation. Different numerical models based on similar hypotheses have been proposed [e.g. 10, 12, 18]. Prendergast et al. [43] proposed a model for mechano-regulated tissue differentiation which assumes that the regenerating tissue is a poroelastic material where the biophysical stimulus regulating differentiation is a function of tissue shear strain and the interstitial fluid flow. This model has successfully predicted tissue differentiation during fracture healing [33], at implant/bone interfaces $[2,25]$ and during osteochondral defect repair [30]. The objective of this paper is to develop upon this model so that it is capable of predicting the evolution in time of the mechanical properties of differentiating tissues. This model will then be used to investigate tissue differentiation after osteotomy of the mandible under the action of mastication forces. In particular, an 
investigation of the latency time and its effects on the bone regeneration process will be carried out. We hypothesize that the mechanics of the mastication will influence the biophysical stimulus within the callus following the osteotomy to such a degree that it will alter the spatial distribution of the callus mechanical properties. An asymmetric distribution of the callus mechanical properties during the latency period is undesirable because in the subsequent distraction process an asymmetric widening of the mandibular arch - with respect to the middle sagittal plane - can occur. Investigating whether or not the changing the length of the latency period, or reducing the mastication loading, will improve the regeneration in the callus are important questions, that can be difficult to answer experimentally, and computational tools such as that presented here are becoming increasingly important in pre-operative planning.

\section{Materials and methods}

\subsection{Mechano-regulation algorithm}

The dispersal of marrow derived mesenchymal stem cells (MSCs) throughout the bone callus can be described using a diffusion equation:

$$
\frac{\mathbf{d} c}{\mathbf{d} t}=D \nabla^{2} c
$$

where $c$ denotes the concentration of MSCs in a given volume and $D$ is the diffusion coefficient. The parameter of Eqn. 1 (i.e. the $D$ diffusion coefficient) was set so that the complete cell coverage in the callus is achieved two weeks after the osteotomy.

As MSCs disperse from the bone marrow throughout the bone callus, the only assumed cell source in this model, they will differentiate into different cell phenotypes based on the value of a biophysical stimulus $S$. Following Prendergast et al., [43], if $\gamma$ is the octahedral shear strain and $v$ the relative fluid/solid velocity, the stimulus $S$ is defined as: 


$$
S=\frac{\gamma}{a}+\frac{v}{b}
$$

$a$ and $b$ being empirical constants [25], where $a=3.75 \%$ and $b=3 \mu \mathrm{ms}^{-1}$. Depending on the value of $S$, each cell changes phenotype (regardless of its current phenotype) such that:

$$
\text { if }\left\{\begin{array}{l}
S>p \Rightarrow \text { fibroblast and fibrous tissue formation } \\
1<S<p \Rightarrow \text { chondrocyte and cartilagineous tissue formation } \\
q_{\text {mature }}<S<1 \Rightarrow \text { osteoblast and immature bone tissue formation } \\
q_{\text {resorb }}<S<q_{\text {mature }} \Rightarrow \text { osteoblast and mature bone tissue formation } \\
0<S<q_{\text {resorb }} \Rightarrow \text { bone resorbtion }
\end{array}\right.
$$

where $q_{\text {mature }}, q_{\text {resorb }}$ and $p$ represent boundaries of the mechano-regulation diagram for tissue differentiation. Their values are taken to be the same as those utilized by Lacroix and Prendergast [33] and Kelly and Prendergast [30] $\left(q_{\text {resorb }}=0.01, q_{\text {mature }}=0.53, p=3\right)$.

\subsection{Development of rate equation for material properties}

Previous models of tissue differentiation have assumed a rapid differentiation from one tissue type to another, and described the subsequent change in the material properties of the tissue using a simple rule of mixtures $[33,30]$. In order to better describe the temporal changes in tissue stiffness as healing progresses within the osteotomized region, it is assumed that the Young's modulus of all tissues within the callus increase exponentially with time. The equation describing the variation of the Young's modulus is of the form:

$$
E_{i}=K_{i} e^{\gamma_{i} \cdot t}
$$

where $E_{i}$ represents the Young's modulus for tissue phenotype $i$ (where $i$ is either fibrous tissue, cartilage, immature or mature bone), $t$ is the time and $K_{i}$ and $\gamma_{i}$ are two parameters regulating the shape of the exponential curve. The values of $K_{i}$ and $\gamma_{i}$ have been set so that the Young's modulus 
of tissue phenotype $i$ increases, in 75 days from the initial value of $0.2 \mathrm{MPa}$, typical of granulation tissue, to the final values reported in Table 1. The same time scale was set for the maturation of fibrous and cartilaginous tissue.

After the calculation of the new tissue phenotype and of the number of the MSCs invading the domain, the algorithm evaluates the mechanical properties for every element based on the exponential law (Eqn. 4) and a simple rule of mixtures. The material properties of every element were calculated as an average of the material properties of ten previous predicted tissue phenotypes. For example, if $\bar{E}$ is the average Young's modulus for a particular element for the ten previous iterations and if $c$ is the concentration of MSCs in a given volume in the iteration iter evaluated with Eqn. 1, then the Young's modulus for that element and for the next iteration iter +1 will be given by:

$$
E(\text { iter }+1)=\frac{c}{c_{\max }} \cdot \bar{E}+\frac{\left(c_{\max }-c\right)}{c_{\max }} \cdot E_{\text {granulation }}
$$

and

$$
\bar{E}=\frac{1}{10} \sum_{n i=p}^{p+10} E_{i}(n i)
$$

where $c_{\max }$ is the maximum concentration of MSCs which may occupy any one element domain, $E_{\text {granulation }}$ is the Young's modulus of the granulation tissue, $n i$ is the number identifying the iteration, $p$ is the number identifying the tenth last iteration and $E_{i}$ is the value of the Young's modulus as determined by Eqn. 4. For the other mechanical properties of the elements (i.e. permeability, Poisson's ratio, liquid and grain Bulk modulus and porosity), as no clear data is available in the literature about their change in time during the differentiation process, it was assumed that their temporal change is described solely by the rule of mixtures detailed above. 


\subsection{Generation of the finite element model}

A 3D model of human mandible (see Fig. 1a) has been reconstructed from CT scan data and the processing of the CT files was made by means of the Mimics ${ }^{\circledR}$ Version 7.2 software (Materialise Inc.). The model also includes an orthodontic distractor tooth-borne device. The distractor consists of one band on the first mandibular molar, and one band on the first mandibular premolar, on both sides of the arch. Bands are steel rings connected by a $1.1 \mathrm{~mm}$ diameter stainless steel wire and a screw positioned behind the lower incisors.

Since the stiffness of the mandibular bone is orders of magnitude greater than the callus, it is possible to model the portion of bone and of the device far from the osteotomized region as a rigid body. Conversely, the portions of the bone, of the bone callus and of the device near to the middle sagittal plane were modelled with 3D deformable elements, i.e. poroelastic elements C3D8P (8 node trilinear displacement and pore pressure; 8 gauss points; active degrees of freedom $u_{1}, u_{2}, u_{3}$ and pore pressure) for the bone and the bone callus and standard hexahedral elements C3D8 (8 node linear brick; 8 gauss points; active degrees of freedom $\left.u_{1}, u_{2}, u_{3}\right)$ for the distraction device. With this strategy we reduce the computational cost of the analysis without introducing significant alterations with respect to the anatomo-physiological behaviour of the mandibular district. The FEM consists of about 12000 3-node un-deformable triangular elements (see Fig. 1b) and 5432 8-node hexahedral elements for meshing the osteotomized region and the deformable portion of the distractor device (Fig. 1d).

Following Meyer et al. [38], a $2 \mathrm{~mm}$ thick callus between the two mandibular ramus was introduced into the model. The callus was meshed using elements $0.25 \mathrm{~mm}$ thick, while elements $0.5 \mathrm{~mm}$ thick were used to mesh the bone tissue on both the right and the left side of the callus (Fig. 2). The callus is surrounded by cortical and cancellous bone. The elements that make up the surrounding bone tissue are attached to the rigid part of the model by tying the nodes of the deformable region with those of the other. Similarly, the deformable portion of the device was bonded to the rigid one by the same strategy. In other words, constraint equations were used in 
order to connect rigidly the deformable portions of the bone and of the device to the rigid ones. Preliminary numerical tests have been performed in order to evaluate the sensitivity of the results obtained with this model to the bone surrounding the callus. Simplified prismatic models of the bone-callus-bone structure shown in Fig. 2a were built with increasing thickness of the portion of the model representing the bone. The sensitivity of the strain and of the pore fluid velocities to the length of the bone was investigated for loading conditions similar to those acting on the bone callus during the mastication phase. It was found that if the bone thickness becomes three times as large as the thickness used in this study, negligible differences (in strains and in fluid flow velocities) arise. Also, preliminary convergence analyses have been performed on the bone callus model, in order to make the model as much as is possible grid independent.

\subsection{Material properties}

The bone callus and adjacent bone tissue were modelled as poroelastic materials. The cortical bone was modelled as an orthotropic material $\left(\mathrm{E}_{11}=20 \mathrm{GPa}, \mathrm{E}_{22}=12 \mathrm{GPa}, \mathrm{E}_{33}=14 \mathrm{GPa} ; \mathrm{v}_{12}=0.36\right.$, $v_{13}=0.33, v_{23}=0.2$ ), the principal material directions and elastic moduli of which have been taken from Schwartz-Dabney and Dechow [48]. The poroelastic properties have been assumed isotropic with a permeability of $1 \cdot 10^{-17} \mathrm{~m}^{4} / \mathrm{Ns}$ [15] for the cortical bone and $1.05 \cdot 10^{-9} \mathrm{~m}^{4} / \mathrm{Ns}$ [41] for the cancellous bone. The material properties used for all other tissues are the same as used in previous models [33], and are listed in Table 1, while the principal material directions $(1,2,3)$ are shown in Fig. 2b.

\subsection{Finite element analysis and boundary conditions}

The FEM model is subjected to four types of boundary conditions applied simultaneously (see Fig. 1b). Boundary condition (i) simulates the temporomandibular joint. The condyles are represented by two reference points at the locations of articulation. These reference points are connected to the mandible arms through coupling constraints. The behaviour of the temporomandibular joint disc is 
modelled by constraining these reference points to three fixed points by means of spring elements aligned to the coordinate system. In this way, the mandible can rotate about an axis defined by the line connecting the two condyles and translate along the coordinate directions.

Boundary condition (ii) models the mastication phase. The action of the most important muscles involved in the mastication process, the masseters, the temporals and the pterygoid muscles, are included. Loads are applied at points where muscles are inserted into the mandibular bone. Coupling constraints allowed us to distribute the force exerted by each muscle on the mandibular surface where they act. Two different mastication loads have been applied on the model: a full mastication load where the values of forces of each muscle are the same as those used in a previous work [7] (see Table 2) and evaluated by Faulkner et al. [17]; secondly a reduced mastication load where the forces developed by each muscle have been reduced by $70 \%$. For each of these two mastication loadings, two different ramp loading periods were investigated, in order to simulate the patient masticating quickly or slowly. In the first simulation the loading is ramped rapidly over a 1 second period, and in the second simulation the loading is ramped over a 120 second time period.

Boundary condition (iii) simulates the unilateral occlusion on one tooth on the left mandibular arm (see details in Fig. 1c). The action of chewing on the mandibular arch is modelled by constraining, with simple-supports preventing $u_{3}$-displacements, the second premolar. In other words, we simulated the unilateral occlusion by preventing the displacements along the direction 3 for the second premolar. Typically the mastication process occurs on one side of the mandibular arch, however in the initial stages of mastication it is reasonable to assume that the occlusion occurs on one tooth in particular.

Boundary condition (iv) models the poroelastic behaviour of the bone callus. Pore pressure equal to zero was set on the external surface of the callus and of the surrounding cortical bone (Fig. $2 b$ and $2 d$ ) while no conditions were imposed on the fluid flow velocity. No value was imposed on the pore pressure or the fluid flow velocity at the interface with the rigid and deformable parts of the mandible. 


\subsection{Implementation of mechano-regulation model}

Eqn. 1 was solved using a mass diffusion element in Abaqus (Hibbitt, Karlsson \& Sorensen, Powtucket, RI, USA). The equations describing cell dispersal and differentiation, is implemented into an algorithm, a graphical summary of which is depicted in Fig. 3. Mastication loads acting on the mandibular bone produce strain and fluid flow within the bone callus. The computation of the biophysical stimulus $S$ is done by using the octahedral shear strain and the velocity fluid flow calculated by the finite element model at the end of the ramp loading. The algorithm computes the biophysical stimulus $S$ (Eqn. 2) and according to Eqn. 3 the new tissue phenotype. At this point, the diffusion analysis calculates the concentration of MSCs invading every element. Based on the exponential law (Eqn. 4) and on a rule of mixtures (Eqns. 5-6) the algorithm evaluates the mechanical properties for every element for the next iteration. Each iteration corresponds to 4.8 hours, that is, the diffusion equation (Eqn. 1) computes the change of cells concentration occurring every 4.8 hours. Therefore, with 75 iterations a period of 15 days is covered, with 5 iterations corresponding to one day.

In order to evaluate how the bone callus mechanical properties distribute with respect to the middle sagittal plane the symmetry coefficient $C_{S}$ was introduced. Let $E_{\text {left }}$ and $E_{\text {right }}$ be the Young's modulus along the latero-lateral direction (i.e. direction 1 in Fig. 1b) of the left and of the right hand side of callus respectively (for more details see Appendix A). If $E_{\text {equivalent }}$ is the Young's modulus in the same 1-direction for the whole bone callus model, the $C_{S}$ symmetry coefficient is given by:

$$
C_{S}=\frac{\left|E_{\text {left }}-E_{\text {right }}\right|}{E_{\text {equivalent }}} \cdot 100
$$

The symmetry coefficient $C_{S}$ has been calculated for a time period of 40 days. It is clear that the symmetry coefficient $C_{S}$ could provide useful informations for the clinicians. A too high value of $C_{S}$ after the latency period, can lead to asymmetric widening of the mandibular arch during the subsequent distraction process. 
Computations are performed on a HP XW4100 workstation with a single $2.8 \mathrm{GHz}$ Intel Pentium IV $\mathrm{CPU}$ and $512 \mathrm{Mb}$ of RAM memory. The computation time is about 30 minutes for each iteration.

\section{Results}

In the case of full mastication loading applied over a ramp period of 120 seconds, the percentage of MSCs within the entire callus differentiating into osteoblasts increases during the latency period, while the percentage of chondrocytes and fibroblasts within the callus decreases (Fig. 4a). Reducing the applied mastication loading is predicted to increase the number of progenitor cells differentiating into osteoblasts and reduce the number of progenitor cells differentiating into chondrocytes. Reducing the ramp time to 1 second is not predicted to have a major effect on the overall differentiation process. In general, the fluid flow within the callus increases and the strain decreases, with a slight overall increase in the biophysical stimulus $S$ within the callus. This results in a slight increase in soft tissue formation and a corresponding decrease in bone formation at both loading magnitudes (see Fig. 4b).

The percentage of MSCs differentiating into osteoblasts is predicted to be greater on the far left side (FLS) compared to the far right section (FRS) (Fig. 5) for the full mastication load. This difference becomes negligible if the mastication loads acting on the mandible are reduced.

The patterns of tissue differentiation are predicted to vary considerably through the thickness of the callus for both the full (Fig. 6) and reduced (Fig. 7) mastication loadings using a ramp loading period of 120 seconds. Similar results are observed for the faster ramp loading (results not shown). A few days after the osteotomy (day 4-6), for either the full or reduced mastication load, the stimulus on the posterior side of the far left section of the callus favours fibrous tissue formation, while a lower mechanical stimulus in the central region of this section favours bone formation. In the central section of the callus the mechanical stimulus is higher and favours a mixture of fibrous and cartilaginous tissue formation for full mastication loading (Fig. 6), or primarily fibrous tissue formation for reduced mastication loading. Fibrous tissue formation is also 
predicted on the anterior side of the far right section (Fig. $6 \& 7$ ). In general, it is predicted that applying a full mastication load will lead to new bone formation by both intramembranous and endochondral ossification (Fig. 6), while primarily intramembranous ossification with little cartilage formation is predicted with reduced mastication loading (Fig. 7).

The change in Young's modulus through the thickness of the callus can be determined by averaging the Young's modulus of each layer of elements that make up the callus model. The Young's modulus is lowest in the centre of the callus (Fig. 8). The Young's modulus of the whole callus increases with time as MSCs invade the region and the new tissues forming within the callus begin to stiffen. Furthermore, in the days following the osteotomy the $C_{S}$ symmetry coefficient (see Methods section) is near to zero but, after the sixth-seventh day increases (Fig. 9). Only for very long latency periods (> 20 days) are significant asymmetries predicted in the mechanical properties of the callus. Greater asymmetries are predicted in the case when full mastication loads are applied for both120 seconds and 1 second ramp loading period.

In order to investigate if premature bone bridging between the two sides of the fracture callus could hinder the subsequent distraction process, the amounts of new bone within the callus with a predicted Young's modulus greater than $0.7 \mathrm{MPa}$ were isolated (see Fig. 10 which illustrates the process of bone formation in the frontal plane 1-3 for the 120 second ramp loading). After seven days, portions of bone tissue linking the left with the right side of the callus are predicted to form in the case of reduced mastication loading, however this process is delayed slightly if full mastication loading is applied (Fig. 10). Similar results are predicted for the faster ramp loading (Fig. 11).

\section{Discussion}

In this paper a finite element model is used in combination with an algorithm that relates tissue differentiation to the mechanical environment to investigate the bone regeneration process in an osteotomized mandible. The objective was to evaluate how the latency period and the mechanics of mastication influence the tissue phenotype within the osteotomy gap. In order to meet this objective, 
a number of modelling assumptions and estimations had to be made. It was assumed that the migration of MSCs from the surrounding bone marrow can be described as a diffusive process, whereas in reality, the convection of MSCs through fluid in the callus also occurs. It was also assumed that the bone marrow was the only source of progenitor cells, however preliminary analyses not presented here predict only a small increase in osteogenesis within the callus if cells also migrate from the surrounding soft tissue and the periostium. Regarding the mechano-regulation algorithm, the limits used for the biophysical stimulus $S$ (Eqn. 2) have yet to be experimentally validated; however they are the same as those employed in previous studies that have successfully predicted the patterns of tissue differentiation observed during fracture healing [33] and osteochondral defect repair [30]. In addition, the patterns of tissue differentiation predicted by a similar algorithm based on deviatoric strain and fluid velocity were shown to be closest to experimental results compared to other mechano-regulation models [28]. However as other mechano-regulation models have not been investigated here, we cannot comment on their ability to predict tissue differentiation in the osteotomized mandible, and it should be noted that other investigators have related patterns of hydrostatic stress and maximum principal tensile strain to patterns of tissue differentiation during mandibular distraction osteogenesis [35]. Another limitation of the model is that no account is made for rate at which MSCs differentiate. At present, it is assumed that differentiation can occur within one iteration of the model, whereas in reality the differentiation process may take longer. Therefore the predictions of the model at early time points must be viewed with caution, as the MSCs may not have had sufficient time to differentiate. This may be one reason for the unphysiological prediction of cartilage formation at early time points, which is generally not observed histologically until later in the latency period. Other conditions may change in the oral cavity not necessarily linked to mastication. For instance, hot/cold irritants could produce thermal variations which may affect the tissue differentiation process. For example, a number of studies have reported that heat stresses can influence cell proliferation [21, 36]. The present model does not consider such effects. 
Concerning the finite element model itself, we modelled the temporo-mandibular joint by combining coupling constrains and spring elements. In reality, the mechanics of this articulation is more complex [9], but nevertheless represents a reasonable approximation to reality. It is difficult to accurately quantify the poroelastic boundary conditions such as the pore pressure boundary conditions in such a model. It has been assumed here that pore pressure was zero on the external surface of the callus and that of the surrounding cortical bone, however this assumption would be invalid in the case of an intact periosteum. No account is made of the forces exerted by soft tissue envelop, which could play an important role in bone relapse. It is also worth noting that chewing is a dynamic task and therefore the assumption that the occlusion is always happening on one side and in one specific location could introduce errors in the computation of the tissue differentiation process. Furthermore, the values of force exerted by each muscle were taken from Faulkner et al. [17] who measured them by using a symmetric recruiting of the muscles on both the controlateral and ipsilateral side, however there are limitations with this approach [46]. The periodontal ligament (PDL) was not included in the finite element model. The micro-movements produced by the PDL could have an influence on the biophysical stimulus $S$ within the callus. The mandibular bone is also more complex than assumed here. It comprises, in addition to the cortical and trabecular bone, the alveolar bone and it is characterized by the presence of the roots, the alveolar sockets and the periodontal ligament. It spite of these limitations it should be noted that the same modelling of the boundary conditions etc. presented in this study was adopted in a previous model [7] where a good agreement was found between in vivo measurements of interdental distances and the corresponding distances predicted by the numerical model. Predicted stress peaks were also found to be consistent with those determined by Basciftci et al. [5].

The computational mechano-biological model proposed here is in a sense deterministic as it predicts the tissue differentiation process for a specific patient with specific characteristics under constant loading conditions. Each time the simulation is run, it will produce the exact same result unless something is changed in the model. In reality, cells and tissues from different people will 
respond differently to identical conditions due to genetic differences. Material properties and mechanical loading will vary from person to person, and even the callus within a single patient will experience mechanical loading that changes with time. No account has been made in the present model for inter-patient variability or for what effect uncertainty in loading etc. has on the tissue differentiation process. The reasons for this are two-fold. Firstly, variations, for example, in the boundaries used in the mechano-regulation diagram (Eqn. 3) due to genetic variation were not considered as to do so could lead to suggestions of tweaking these boundaries in order to match model predictions to experimental findings. Secondly, the computational cost of running these simulations is very large, and introducing statistical variation would be prohibitively costly. As computational power increases, it will be possible to run such simulations.

An exponential increase of the Young's modulus in time was assumed. This choice is based on the results of Richardson et al. [44] who observed an exponential increase in stiffness during tibial fracture healing. The period of 75 days was chosen based on an average of times reported for the consolidation and the calcification of the fracture callus $[13,27]$. The same time scale was set for all tissue types, however in reality one might expect different rates to apply to different tissues. In an attempt to partially access the validity of this approach, the predictions of the model were compared to the results of Robinson et al. [45] who measured the distraction force necessary for expanding the bone callus of human mandibles submitted to hemimandibular osteotomies. Following a six day latency period they found a mean force of $35.6 \pm 13.43$ N. However this value also takes into account the force required to expand the soft tissues surrounding the bone callus. To determine the effect of the bone callus alone for comparison with the model presented here, the measured force value was decreased by $25 \%$ (according to Aronson [4] and Hollis [23]), resulting in a force of $26.7 \pm 10.07 \mathrm{~N}$. It is possible to use the computational model to simulate a distraction of the bone callus after a latency period of 6 days - i.e. by simulating the expansion of a bone callus with the mechanical properties computed at the sixth day of the latency period - through imposing a displacement of $0.5 \mathrm{~mm}$ along the direction 1 (for direction 1, see Fig. 1b) over a time of 60 
seconds. In this case, a distraction force of $35.8 \mathrm{~N}$ and $35.1 \mathrm{~N}$ was predicted in the case of full mastication loads for a ramp loading time of 120 seconds and 1 second respectively, while a distraction force of $41.3 \mathrm{~N}$ and $37.7 \mathrm{~N}$ was predicted in the case of the reduced mastication loading for a ramp loading time of 120 seconds and 1 second respectively. It appears that the values of forces predicted by the computational model in the case of full mastication loadings fall within the range mean \pm standard deviation found by Robinson et al. [45], while the values of force computed in the case of the reduced mastication loading are higher than found experimentally. Further validation of such evolution equations will be required in the future.

Certain modelling assumptions adopted in this study are therefore different to those adopted by Lacroix and Prendergast [33] and others. In that study, in order to account for the delay between the time that stimuli first act on the cells and the process of differentiation into a new phenotype, the material properties of an element in their model were calculated as an average of the 10 previously predicted tissue phenotypes. This approach was further developed here in order to account for the fact that mesenchymal cells not only require time to differentiate, but that the differentiated cell types require time to synthesise and remodel a new tissue. Indeed, a more precise formulation should account for the fact that the mechanical stimulus acting on the cells will also regulate the temporal change in tissue mechanical properties. The introduction of evolution equations describing the temporal changes in tissue properties as a function of the tissue type and of the biophysical stimulus would be a worthwhile addition to future models. Also the diffusion coefficient $D$ used in this study is different with respect to that used in Lacroix and Prendergast [33]. In the latter work $D$ is set so that the MSCs cover totally the bone callus within 16 weeks which is the typical time for the tibial fracture healing. Here, a diffusion coefficient $D$ was set such that the bone callus coverage by MSCs occurs in two weeks. To the author's knowledge, no clear information is available in the literature about the dispersal rate of the MSCs within a mandibular fracture callus.

New bone formation is initially predicted at the osteotomy edges (Fig. 10, Fig. 11). This result is consistent with histological analyses carried out by Uhthoff and Rahn [50] in a dog model, 
which shows that one week post-osteotomy, new bone begins to form around the existing original bone on either side of the fracture gap. Loboa et al. [34] observed new bony trabeculae along the periosteal edges of the osteotomies after a latency period of 5 days, with the distraction gap containing disorganised collagen, but no new bone formation. The model predicts a thin region of fibrous tissue formation along one edge of the callus in each section analysed (Fig. 6, Fig. 7), whereas in reality one would expect bone formation in these regions of the callus. This is due to the high strains predicted in this region of the bone callus. However one might expect these periosteal regions to be highly vascularised, and perhaps bone formation is possible in such regions even under intermediate magnitudes of strain. Taking account of the vascular environment within the callus will be an important addition to future models. After a latency period of 5 days, the model predicts that over $20 \%$ of cells within the callus are osteoblasts with full mastication loading at the slower ramp loading, with approximately $37 \%$ of cells predicted to be osteoblasts with reduced mastication loading. Similar results are predicted for the faster ramp loading. While it is unlikely at this early stage that a mineralised matrix would be produced, it does indicate that osteogenesis is being supported within the callus, particularly at reduced mastication loads. The mechanism through which new bone forms (intramembranous or endochondral) would also appear to depend on the mastication loading. It is predicted that bone forms through both intramembranous and endochondral ossification with full mastication loading, while intramembranous ossification with very little cartilage tissue formation is predicted with reduced mastication loading. A number of animal model studies investigating distraction osteogenesis have also revealed that the mechanism of bone formation within an osteotomized mandible would appear to depend on the mechanical environment within the callus. Kessler et al. [31] observed cartilage formation only after intermittent bone distraction, when the device was distracted by $1.5 \mathrm{~mm}$ once a day, whereas intramembranous bone formation was observed when a continuous distraction of $1.5 \mathrm{~mm}$ was applied over the course of the day. In addition, Meyer et al. [37] observed that the magnitude of distraction applied to osteotomised mandibles can regulate the type of tissue that forms within the 
callus. However, in general cartilage tissue formation is not observed in vivo until late in the latency period, and the early predictions of cartilage formation by the model indicate that either the limitations of the model discussed earlier will need to be addressed to improve the validity of the mechano-regulation model, or that the fundamental hypotheses (Eqn 2 and 3) on which the model is based will have to be altered to more accurately predict tissue differentiation within membranous bones such as the mandible.

Results show that, in the case of full mastication loading, bone formation proceeds more slowly on the far right section of the bone callus compared to the far left section (Fig. 5). This is because the boundary conditions acting on the bone callus are asymmetric due to the occlusion on the right mandibular ramus. This boundary condition results in a reaction force and subsequently a biophysical stimulus $S$ which is greater on the far right hand side compared to the far left hand side. The effects of such an asymmetric boundary condition become less evident when the mastication loading is reduced by $70 \%$ (Fig. 5). These asymmetric boundary conditions may result in an asymmetric distribution of the bone callus mechanical properties with respect to the middle sagittal plane. As tissue differentiation and bone regeneration proceeds the bone callus becomes an inhomogeneous and anisotropic structure. In general, the ideal situation would be that these asymmetries tend towards zero. In such a case, the subsequent distraction of the bone callus beginning after the latency period - by means of the distractor orthodontic device will produce a symmetric deformation of the osteotomized gap and then a more symmetric expansion of the whole mandibular arch. The results presented here show that the asymmetries within the callus mechanical properties are negligible for latency periods less than 20 days (Fig. 9). However, considering that typical latency periods last less than 14 days [27], such asymmetries are not clinically relevant. Perhaps more importantly, it is predicted that after the seventh-eighth day, bone bridges link the left with the right side of the bone callus (Fig. 10,11). The presence of bone bridges may hinder the distraction process. This suggests that is better to apply clinical protocols with latency periods not longer than seven-eight days so that the risk of a premature bone union is avoided. This is in 
agreement with Conley and Legan [13] who suggest a latency period of seven days.

\section{Conclusion}

A mechano-regulation model was developed to investigate the influence of the duration of the latency period on tissue differentiation and bone regeneration prior to mandibular distraction osteogenesis. Two different mastication loadings have been investigated, a full mastication load and a mastication load reduced by $70 \%$. The mechano-regulation model simulates the evolution in time of the mechanical properties of the bone callus formed in the osteotomized region. It was found that for the full mastication loading, both intramembranous and endochondral ossification are predicted to occur, whereas, for the reduced mastication loading, primarily intramembranous ossification is predicted. Finally, the model predicts that the optimal duration for the latency period is about seveneight days. For such a latency period the risk of a premature bone union of the osteotomy fronts is low and significant amounts of new bone tissue has formed in the callus. 


\section{References}

[1] Anderson CB (1967) Mechanics of fluids. In: Baumeister, T. (Ed.), Marks' Saturated Handbook of Mechanical Engineers, pp. 3.48-3.76.

[2] Andreykiv A, Prendergast PJ, van Keulen F, Swieszkowski W, Rozing PM (2005) Bone ingrowth simulation for a concept glenoid component design. J Biomech 38:1023-1033.

[3] Armstrong CG, Mow VC (1982) Variations in the intrinsic mechanical properties of human articular cartilage with age, degeneration and water content. J Bone Joint Surg 64A:88-94.

[4] Aronson J: Mechanical factors generated during distraction osteogenesis. The International Society for Fracture Repair, Ottrot, France, April 1992

[5] Basciftci FA, Korkmaz HH, Iseri H, Malkoc S (2004) Biomechanical evaluation of mandibular midline distraction osteogenesis by using finite element method. Am J Orthod Dentofac 125:706-715.

[6] Barbieri G, Barbieri CH, de Matos PS, Pelá CA, Mazzer N (2005) Ultrasonometric evaluation of the healing of a transverse diaphyseal osteotomy in different periods. Experimental study in sheep tibiae. Acta Ortopedica Brasileira 13(2):61-67.

[7] Boccaccio A, Lamberti L, Pappalettere C, Carano A, Cozzani M (2006a) Mechanical behaviour of an osteotomized mandible with distraction orthodontic devices. J Biomech 39:2907-2918.

[8] Boccaccio A, Lamberti L, Pappalettere C, Cozzani M, Siciliani G (2006b) Comparison of different orthodontic devices for mandibular symphyseal distraction osteogenesis: a finite element study. Am J Orthod Dentofac, In Press.

[9] Beek M, Koolstra JH, Van Ruijven LJ, Van Eijden TMGJ (2000) Three-dimensional finite element analysis of the human temporomandibular joint disc. J Biomech 33:307-316.

[10] Carter DR, Blenman PR, Beaupré GS (1998) Correlations between mechanical stress history and tissue differentiation in initial fracture healing. J Orthop Res 6:736-748.

[11] Cattaneo PM, Kofod T, Dalstra M, Melsen B (2005) Using the finite element method to model the biomechanics of the asymmetric mandible before, during and after skeletal correction by distraction osteogenesis. Comput Methods Biomech Biomed Engin 8(3):157-65.

[12] Claes LE, Heigele CA (1999) Magnitudes of local stress and strain along bony surfaces predict the course and type of fracture healing. J Biomech 32:255-266.

[13] Conley R, Legan H (2003) Mandibular symphyseal distraction osteogenesis: diagnosis and treatment planning considerations. Angle Orthod 73:3-11.

[14] Costantino PD, Friedman CD, Shindo ML, Houston CG, Sisson GA (1993) Experimental mandibular regrowth by distraction osteogenesis long term results. Arch Otolaryngol Head Neck Surg 119:511516.

[15] Cowin SC (1999) Bone poroelasticity. J Biomech 32:217-238.

[16] Del Santo M, Guerrero CA, Buschang PH, English J, Samchukov L, Bell W (2000) Long-term skeletal and dental effects of mandibular symphyseal distraction osteogenesis. Am J Orthod Dentofac 118:485493.

[17] Faulkner MG, Hatcher DC, Hay A (1987) A three-dimensional investigation of temporomandibular joint loading. J Biomech 20:997-1002.

[18] Gòmez-Benito MJ, Garcìa-Aznar JM, Kuiper JH, Doblaré M (2005) Influence of fracture gap size on the pattern of long bone healing: a computational study. J Theor Biol 235:105-109.

[19] Guerrero CA, Contasti GI (1992) Transverse (horizontal) mandibular deficiency. In: Modern Practice in Orthognathic and Reconstructive Surgery (Bell, W.H. Editor). Saunders, Philadelphia (USA), pp. 2383-2397.

[20] Guerrero CA, Bell WH, Contasti GI, Rodriguez AM (1997) Mandibular widening by intraoral distraction osteogenesis. Br J Oral Maxillofac Surg 35:383-92.

[21] Halevy O, Krispin A, Leshem Y, McMurtry JP, Yahav S. Early-age heat exposure affects skeletal muscle satellite cell proliferation and differentiation in chicks. Am J Physiol Regul Integr Comp Physiol. 2001 Jul;281(1):R302-9

[22] Herberger RJ (1981) Stability of mandibular intercuspid width after long periods of retention. Angle Orthod 51:78-83.

[23] Hollis JM, Aronson J, Hofmann OE (1992). Differential loads in tissues during limb lengthening. Trans Orthop Res Soc 38: 14.

[24] Hori RY, Lewis JL (1982) Mechanical properties of the fibrous tissue found at the bone cement 
interface following total joint replacement. J Biomed Mater Res 16:911-927.

[25] Huiskes R, van Driel WD, Prendergast PJ, Søballe K (1997) A biomechanical regulatory model of periprosthetic tissue differentiation. J Mater Sci Mater Med 8: 785-788.

[26] Ilizarov GA (1989) The tension stress effect on the genesis and growth of tissues. Part I, the influence of stability of fixation and soft tissue preservation; Part II, the influence of the rate and frequency of distraction. Clin Orthop 238:249-285.

[27] Imola JM (2004) Craniofacial distraction osteogenesis. http://www.emedicine.com/ent/topic702.htm

[28] Isaksson H, van Donkelaar CC, Huiskes R, Ito K (2006) Corroboration of mechano-regulatory algorithms for tissue differentiation during fracture healing: comparison with in vivo results. J Orthop Res 24(5):898-907.

[29] Kaspar D, Neidlinger-Wilke C, Holbein O, Claes L, Ignatius A (2003) Mitogens are increased in the systemic circulation during bone callus healing. J Orthop Res 21:320-325.

[30] Kelly DJ, Prendergast PJ (2005) Mechano-regulation of stem cell differentiation and tissue regeneration in osteochondral defects. J Biomech 38:1413-1422.

[31] Kessler P, Neukam FW, Wiltfang J (2005) Effects of distraction forces and frequency of distraction in bony regeneration. Br J Oral Maxillofac Surg 43:392-398.

[32] Kofod T, Cattaneo PM, Dalstra M, Melsen B (2005) Three-dimensional finite element analysis of the mandible and temporomandibular joint during vertical ramus elongation by distraction osteogenesis. $\mathrm{J}$ Craniofac Surg 16(4):586-93.

[33] Lacroix D, Prendergast PJ (2002) A mechano-regulation model for tissue differentiation during fracture healing: analysis of gap size and loading. J Biomech 35:1163-1171.

[34] Loboa EG, Fang TD, Warren SM, Lindsey DP, Fong KD, Longaker MT, Carter DR (2004) Mechanobiology of mandibular distraction osteogenesis: experimental analyses with a rat model. Bone 34:336-343.

[35] Loboa EG, Fang TD, Parker DW, Warren SM, Fong KD, Longaker MT, Carter DR (2005) Mechanobiology of mandibular distraction osteogenesis: finite element analyses with a rat model. J Orthop Res 23:663-670.

[36] Luo XF, Luo XD, Wang XY. Thermal stress can inhibit proliferation of ECV304 cells. Chin J Traumatol. 2003 Feb;6(1):8-11.

[37] Meyer U, Meyer T, Wiesmann HP, Kruse-Lösler B, Vollmer D, Stratmann U, Joos U (2001) Mechanical tension in distraction osteogenesis regulates chondrocytic differentiation. Int $\mathbf{J}$ Oral Maxillofac Surg 30:522-530.

[38] Meyer U, Kleinheinz J, Joos U (2004) Biomechanical and clinical implications of distraction osteogenesis in craniofacial surgery. J Craniomaxillofac Surg 32:140-149.

[39] Mora G, Forriol F (2000) Mechanical analysis of the healing of different osteotomies fixed externally. Int Orthop 24:295-298.

[40] McNamara JG, Brudon WM (1993) Orthodontic and orthopaedic treatment in the mixed dentition. Ann Arbor (MI): Needham Press; pp. 131-145.

[41] Ochoa JA, Hillberry BM (1992) Permeability of bovine cancellous bone. Trans. of the 38th ORS, p. 162.

[42] Pauwels F (1960) Eine neue theorie über den einflu $\beta$ mechanischer reize auf die differenzierung der stützgewebe. Z Anat Entwickl. Gesch. 121, 478-515. Translated as A new theory concerning the influence of mechanical stimuli on the differentiation of the supporting tissues. In: Maquet, P., Furlong, R., (Eds) Biomechanics of the Locomotor apparatus, Springer, Berlin, 1980, pp. 375-407.

[43] Prendergast PJ, Huiskes R, Søballe K (1997) Biophisical stimuli on cells during tissue differentiation at implant interfaces. J Biomech 30:539-548.

[44] Richardson JB, Kenwright J, Cunningham JL (1992) Fracture stiffness measurement in the assessment and management of tibial fractures. J Clin Biomech 7:75-79.

[45] Robinson R, O'Neal PJ, Robinson GH (2001). Mandibular distraction force: laboratory data and clinical correlation. J Oral Maxillofac Surg 59: 539-544.

[46] Ross CF, Patel BA, Slice DE, Strait DS, Dechow PC, Richmond BG, Spencer MA (2005) Modeling masticatory muscle force in finite element analysis: sensitivity analysis using principal coordinates analysis. Anat Rec A 283(A): 288-299.

[47] Schaffer MB, Burr DB (1988) Stiffness of compact bone: effects of porosity and density. J Biomech 21:13-16.

[48] Schwartz-Dabney CL, Dechow PC (2003) Variations in cortical material properties throughout the 
human dentate mandible. Am J Phys Anthropol 120:252-277.

[49] Tepic S, Macirowsky T, Mann RW (1983) Mechanical properties of articular cartilage elucidated by osmotic loading and ultrasound. Proceedings of the National Academy of Sciences USA 80, 33313333.

[50] Uhthoff HK, Rahn BA (1981) Healing patterns of metaphyseal fractures. Clin Orthop 160:295-303.

[51] Weil TS, Van Sickles J, Payne J (1997) Distraction osteogenesis for correction of transverse mandibular deficiency: a preliminary report. J Oral Maxillofac Surg 55:953-960.

[52] Hibbit, Karlsson \& Sorensen, ABAQUS ${ }^{\circledR} 6.4$ User’s Manual, 2004. 


\section{APPENDIX A \\ EVALUATION OF THE SYMMETRY COEFFICIENT}

The callus consists of 8 layers of elements. Its axial stiffness along 1 direction can be described by schematizing the callus as a set of springs arranged in series. Each spring will have a length equal to the thickness of each layer. If $E\left(L_{i}\right), i=\{1,2,3, \ldots, 8\}$, is the mean value of the Young's modulus

calculated in $L_{i}$ layer, and $E_{\text {equivalent }}$ is the Young's modulus in the 1 direction for the whole bone callus model, the $C_{S}$ symmetry coefficient is given by:

$$
C_{S}=\frac{\left|E_{\text {left }}-E_{\text {right }}\right|}{E_{\text {equivalent }}} \cdot 100
$$

where $E_{\text {left }}, E_{\text {right }}$ and $E_{\text {equivalent }}$ are given by:

$$
\begin{gathered}
E_{\text {left }}=\frac{\frac{S_{T O T}}{2}}{S_{L} \sum_{1}^{4} \frac{1}{E\left(L_{i}\right)}} \\
E_{\text {right }}=\frac{\frac{S_{T O T}}{2}}{S_{L} \sum_{5}^{8} \frac{1}{E\left(L_{i}\right)}} \\
E_{\text {equivalent }}=\frac{S_{T O T}}{S_{L} \sum_{1}^{8} \frac{1}{E\left(L_{i}\right)}}
\end{gathered}
$$


and where $S_{L}$ and $S_{T O T}$ are the thickness of each layer of elements and of the entire model respectively. Considering that $S_{L}=S_{T O T} / 8$, therefore Eqn. A2 can be rewritten as:

$$
\begin{aligned}
& E_{\text {left }}=\frac{4}{\sum_{1}^{4} \frac{1}{E\left(L_{i}\right)}} \\
& E_{\text {right }}=\frac{4}{\sum_{5}^{8} \frac{1}{E\left(L_{i}\right)}} \\
& E_{\text {equivalent }}=\frac{8}{\sum_{1}^{8} \frac{1}{E\left(L_{i}\right)}}
\end{aligned}
$$

It is known that Eqn. A3 (corresponding to the so called Reuss' model) underestimate the elastic modulus. Another possible way of estimating the Young's modulus could be to perform a FE analysis of a compression test of the gap every analysis step. However, such a strategy would be significantly more expensive in terms of computation. 


\section{TABLES}

Table 1. Material properties utilized in FEM analyses for the bone callus

\begin{tabular}{|c|c|c|c|c|c|}
\hline Material & $\begin{array}{c}\text { Granulation } \\
\text { tissue }\end{array}$ & Fibrous tissue & Cartilage & $\begin{array}{c}\text { Immature } \\
\text { bone }\end{array}$ & Mature bone \\
\hline \multirow{3}{*}{$\begin{array}{c}\text { Young' Modulus } \\
{[\mathrm{MPa}]} \\
\text { Permeability } \\
{\left[\mathrm{m}^{4} / \mathrm{Ns}\right]} \\
\text { Poisson's Ratio }\end{array}$} & 0.2 [33] & 2 [24] & 10 [33] & $1000[33]$ & 6000 [12] \\
\hline & $1 * 10^{-14}[33]$ & $1 * 10^{-14}[24]$ & $5 * 10^{-15}[3]$ & $1 * 10^{-13}[33]$ & $3.7 * 10^{-13}[41]$ \\
\hline & 0.167 [33] & 0.167 [33] & 0.167 [33] & 0.3 [33] & 0.3 [33] \\
\hline \multirow{3}{*}{$\begin{array}{c}\text { Bulk Modulus Grain } \\
{[\mathrm{MPa}]} \\
\text { Bulk Modulus Liquid } \\
{[\mathrm{MPa}]} \\
\text { Porosity }\end{array}$} & $2300[1]$ & $2300[1]$ & $3400[49]$ & $13920[15]$ & 13920 [15] \\
\hline & $2300[1]$ & $2300[1]$ & $2300[1]$ & $2300[1]$ & $2300[1]$ \\
\hline & $0.8[33]$ & 0.8 [33] & 0.8 [33] & 0.8 [33] & 0.8 [33] \\
\hline
\end{tabular}

Table 2. Components of muscular forces on mandible

\begin{tabular}{|c|c|c|c|}
\hline \multirow{2}{*}{$\begin{array}{l}\text { Muscles } \\
\text { Right side }\end{array}$} & \multicolumn{3}{|c|}{$\begin{array}{c}\text { Components of muscular } \\
\text { forces }[\mathrm{N}]\end{array}$} \\
\hline & $\overline{F_{X}}$ & $\overline{\mathrm{F}_{\mathrm{Y}}}$ & $\overline{F_{Z}}$ \\
\hline Posterior temporalis & -15.4 & -2.03 & 12.97 \\
\hline Anterior temporalis & -7.44 & -1.53 & 20.56 \\
\hline Medial pterygoid & 0.49 & -5.2 & 15.27 \\
\hline Lateral pterygoid & -6.98 & -1.85 & -1.85 \\
\hline Superficial masseter & 1.47 & 2.65 & 9.34 \\
\hline Deep masseter & -2.46 & 3.68 & 12.83 \\
\hline \multicolumn{4}{|l|}{ Left side } \\
\hline Posterior temporalis & -8.39 & 1.10 & 7.06 \\
\hline Anterior temporalis & -9.49 & -1.95 & 26.23 \\
\hline Medial pterygoid & 0.52 & -5.52 & 16.22 \\
\hline Lateral pterygoid & -6.98 & -1.85 & -1.85 \\
\hline Superficial masseter & 3.04 & 5.47 & 19.26 \\
\hline Deep masseter & -4.94 & 7.42 & 25.84 \\
\hline
\end{tabular}

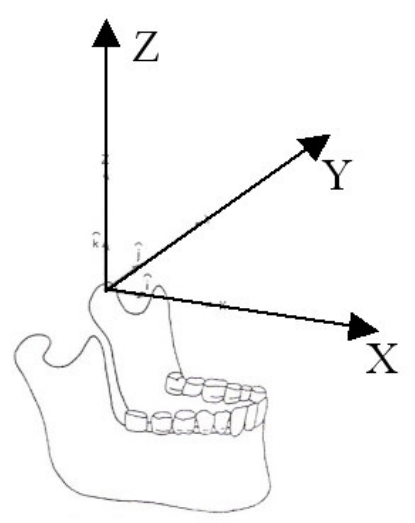




\section{Figure Legends}

Figure 1. (a) Epoxy resin model; (b) mandible-distractor orthodontic device FEM model, illustrating the coordinate system and the boundary conditions used; (c) details of the unilateral occlusion on the second premolar; (d) Details of the osteotomized region and of the tooth borne device.

Figure 2. (a) FEM model of the osteotomized zone. Different regions and materials included in the model: (b) cortical bone, (c) cancellous bone, (d) fracture callus.

Figure 3. Schematic of the implemented mechano-regulation algorithm.

Figure 4. Phenotype of cells composing the bone callus for full mastication loading and for mastication loading reduced by $70 \%$ : (a) mastication loading applied over a ramp period of 120 seconds; (b) mastication loading applied over a ramp period of 1 second.

Figure 5. Bone percentage on the Far Left Section (FLS), Far Right Section (FRS) and Central Section (CS) for a full mastication loading and for a mastication loading reduced by $70 \%$. Mastication loadings are applied over a ramp period of 120 seconds.

Figure 6. Tissue differentiation and mechanical properties of the bone callus computed with the mechano-regulation algorithm. Full mastication loads are applied. Mastication loading is applied over a ramp period of 120 seconds.

Figure 7. Tissue differentiation and mechanical properties of the bone callus computed with the mechano-regulation algorithm. Mastication loads are reduced by $70 \%$. Mastication loading is applied over a ramp period of 120 seconds.

Figure 8. Mechanical properties of the bone callus at different time steps. Full mastication loads are applied over a ramp period of 120 seconds. The value reported for each location along the section is an average value of the Young's modulus computed over the entire transverse section.

Figure 9. Symmetry coefficient $C_{S}$ at different days since the osteotomy for full mastication loads and for mastication loads reduced by $70 \%$. The mastication loading is applied over a ramp period of either 120 seconds or 1 second.

Figure 10. 3D visualization of the bone regeneration process, where mastication loads are applied over a ramp period of 120 seconds. (a) Full mastication loads are applied. (b) Mastication loading reduced by $70 \%$ are applied.

Figure 11. 3D visualization of the bone regeneration process, where mastication loads are applied over a ramp period of 1 second. (a) Full mastication loads are applied. (b) Mastication loading reduced by $70 \%$ are applied. 


\section{FIGURES}
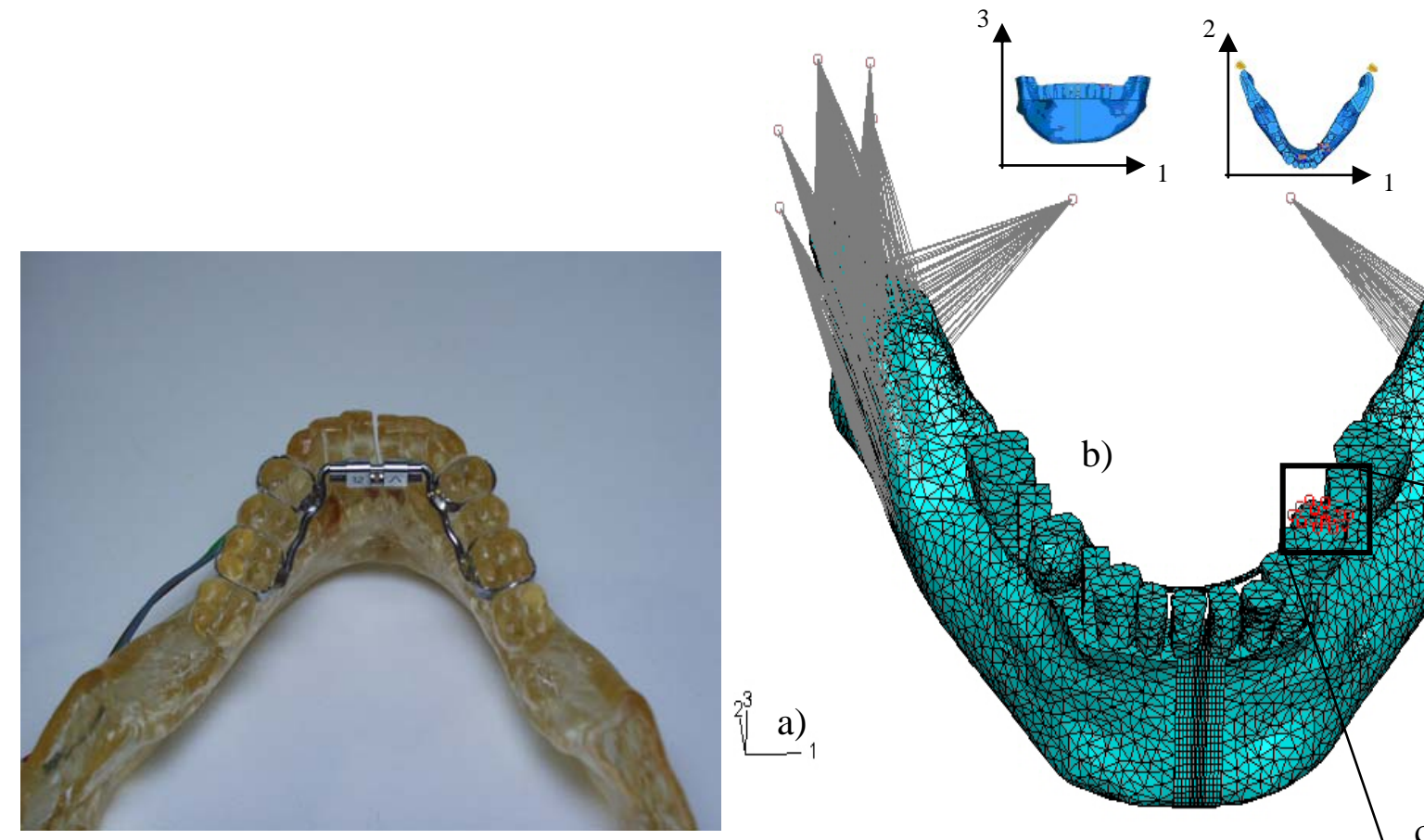

a)

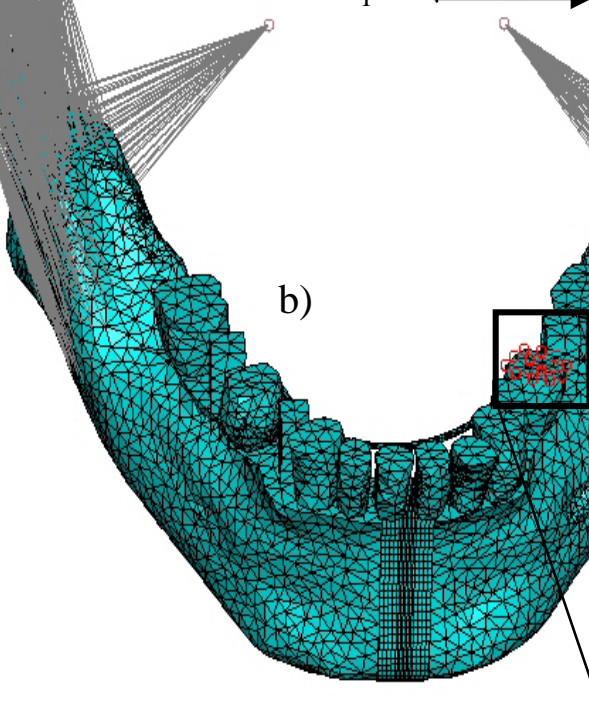

c)

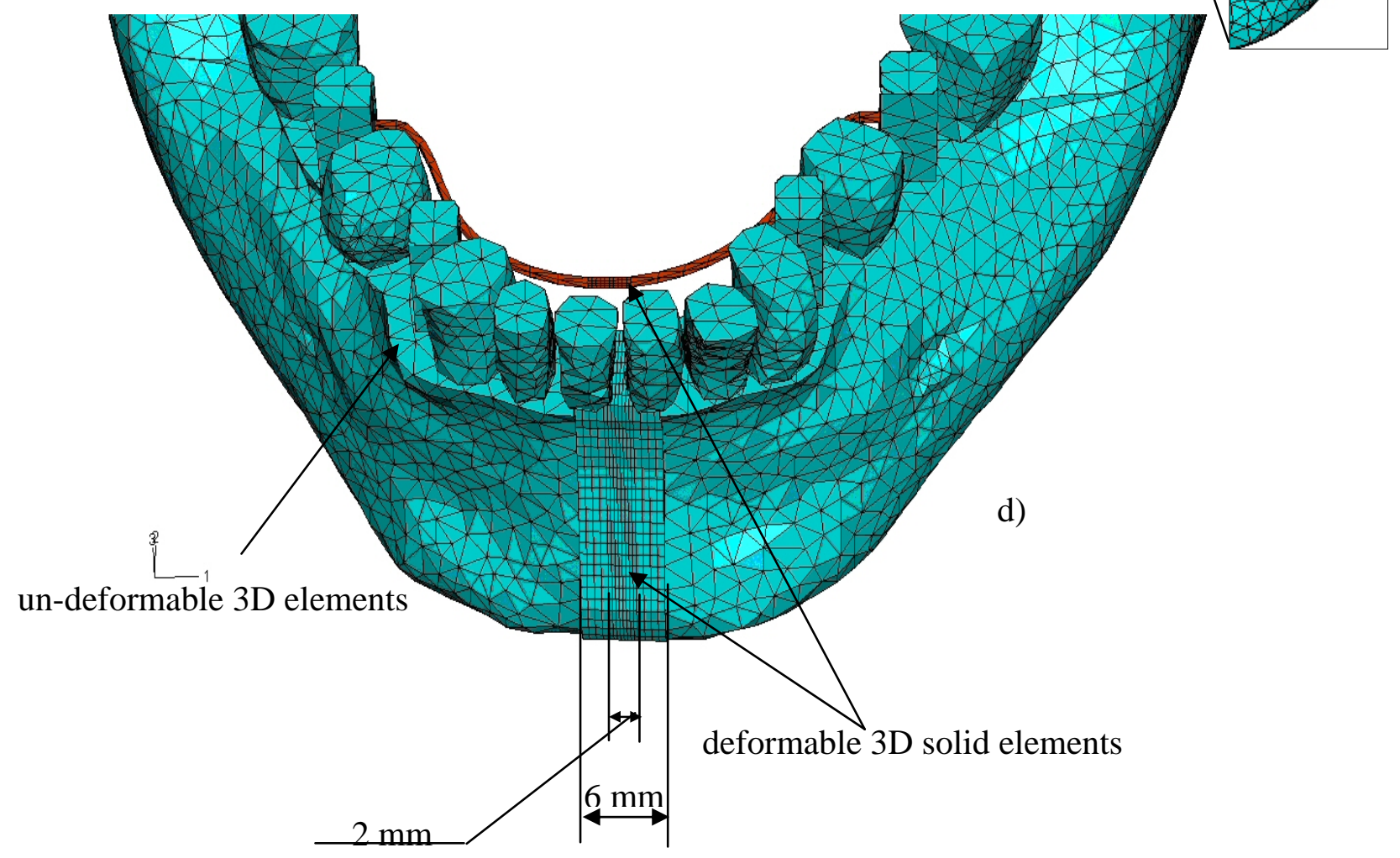

Figure 1. (a) Epoxy resin model; (b) mandible-distractor orthodontic device FEM model, illustrating the coordinate system and the boundary conditions used; (c) details of the unilateral occlusion on the second premolar(d) Details of the osteotomized region and of the tooth borne device 

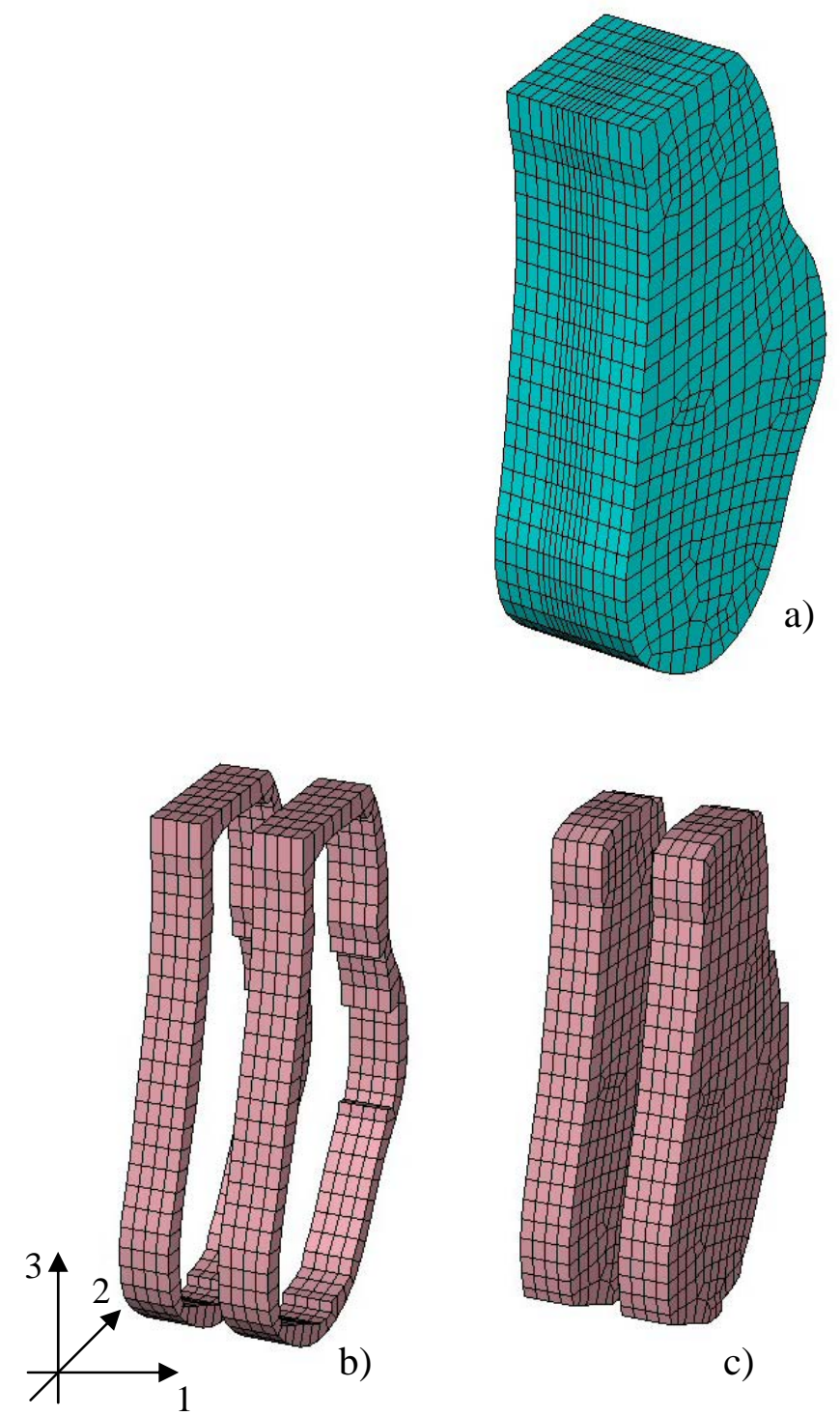

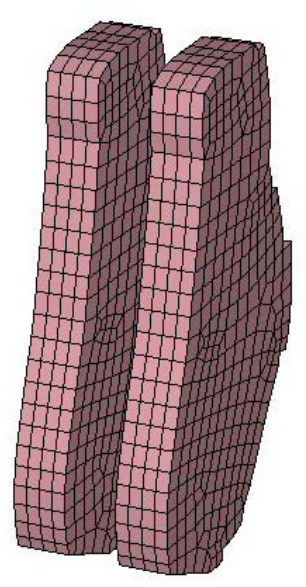

c)

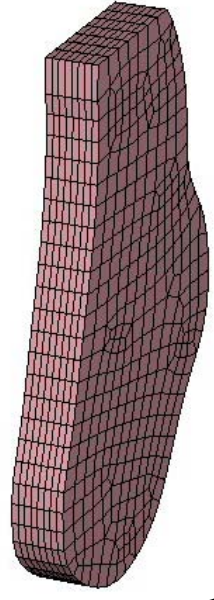

d)

Figure 2. (a) FEM model of the osteotomized zone. Different regions and materials included in the model: (b) cortical bone, (c) cancellous bone, (d) fracture callus. 


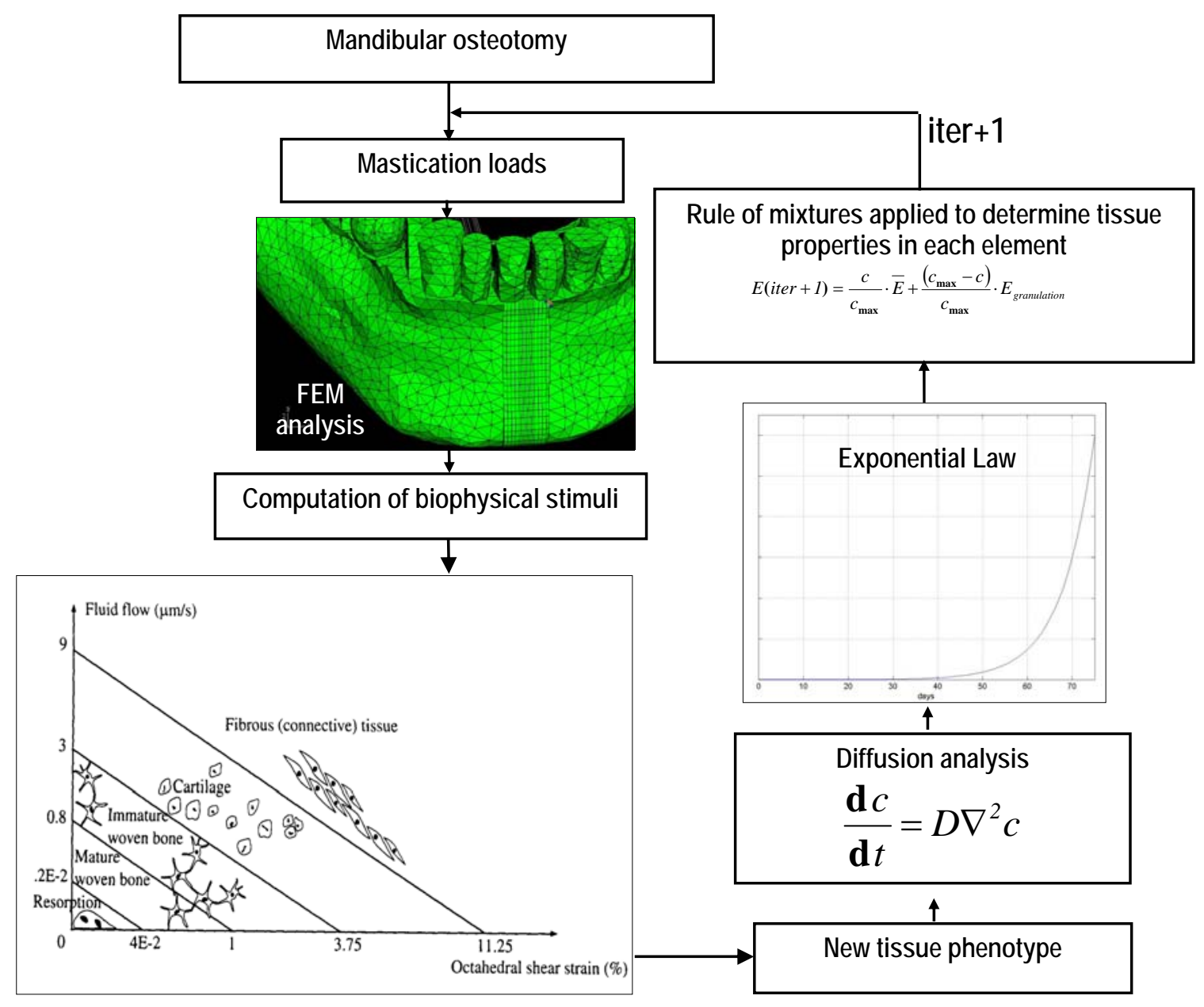

Figure 3. Schematic of the implemented mechano-regulation algorithm 


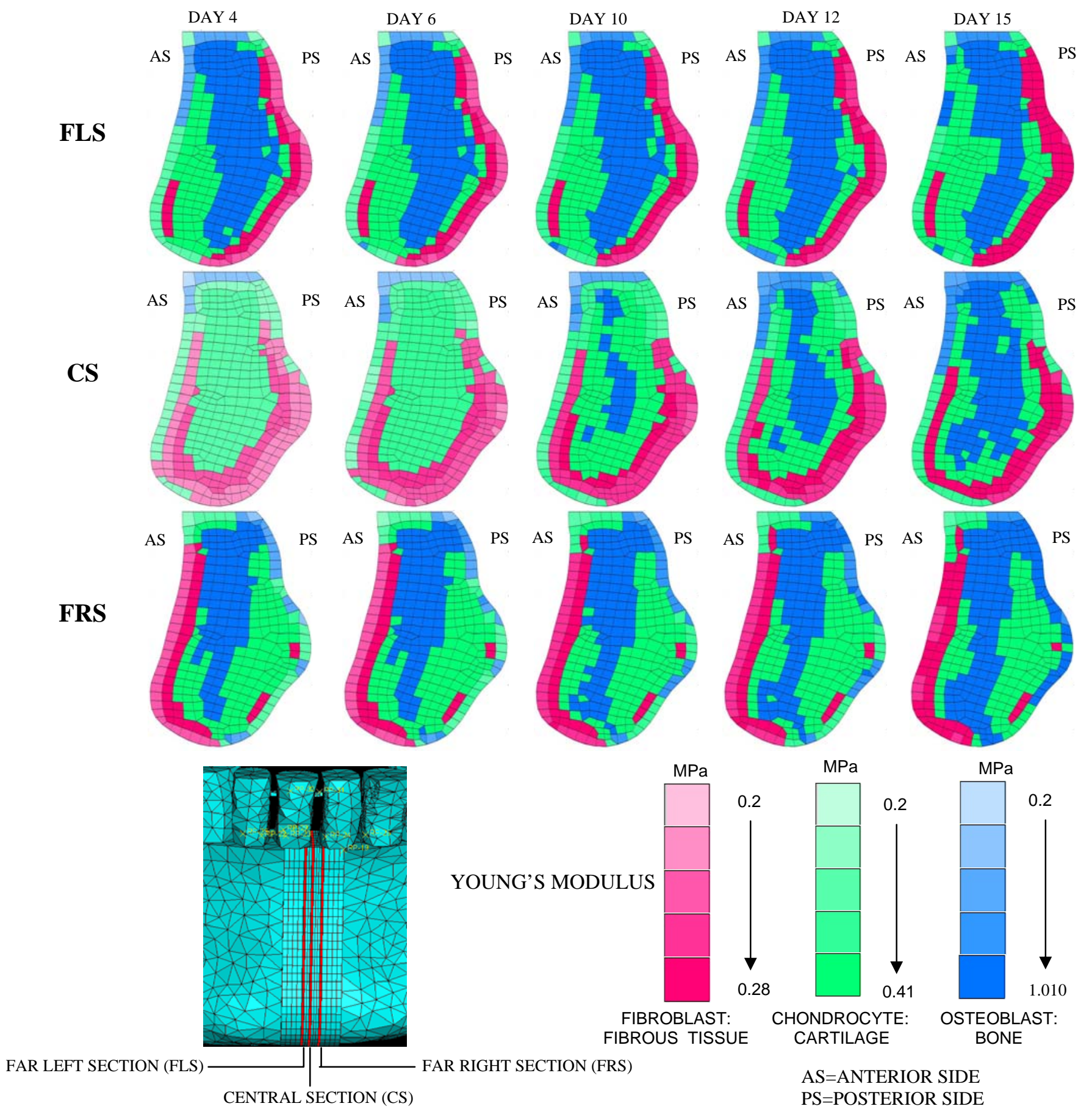

Figure 4. Tissue differentiation and mechanical properties of the bone callus computed with the mechano-regulation algorithm. Full mastication loads are applied. 


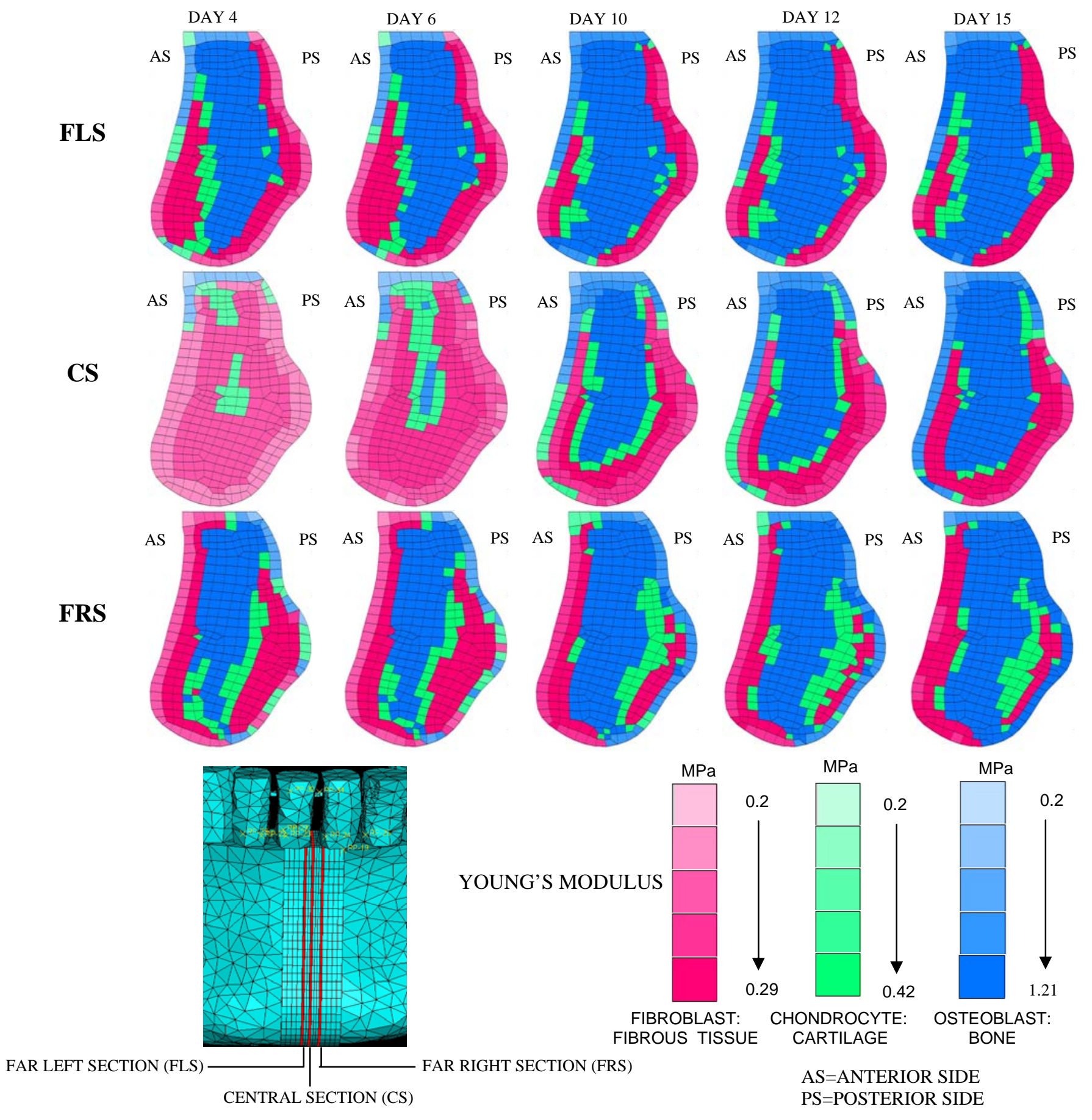

Figure 5. Tissue differentiation and mechanical properties of the bone callus computed with the mechano-regulation algorithm. Mastication loads are reduced by $70 \%$. 


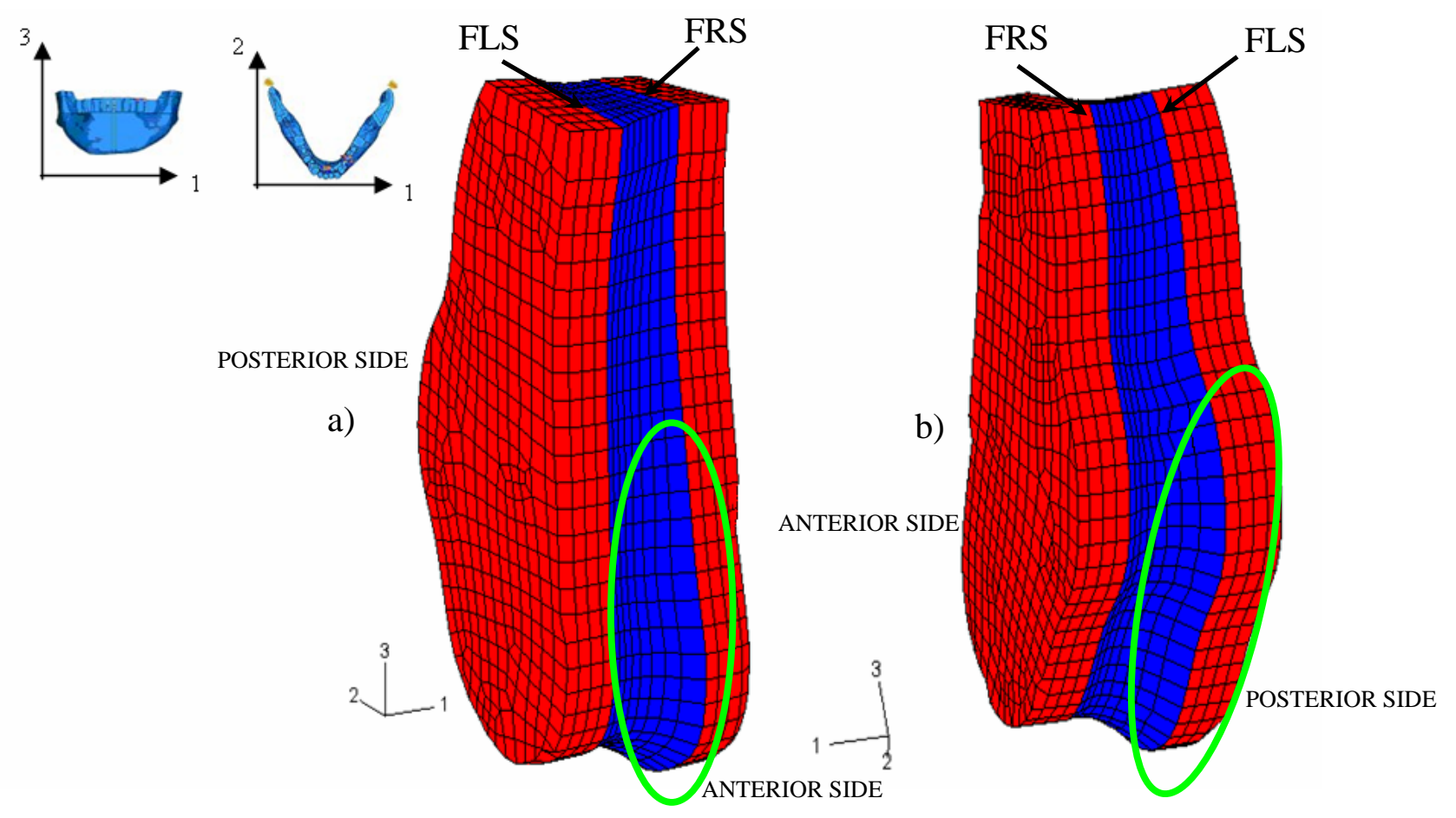

Figure 6. Deformation of the bone callus: (a) anterior view and (b) posterior view 
(a)

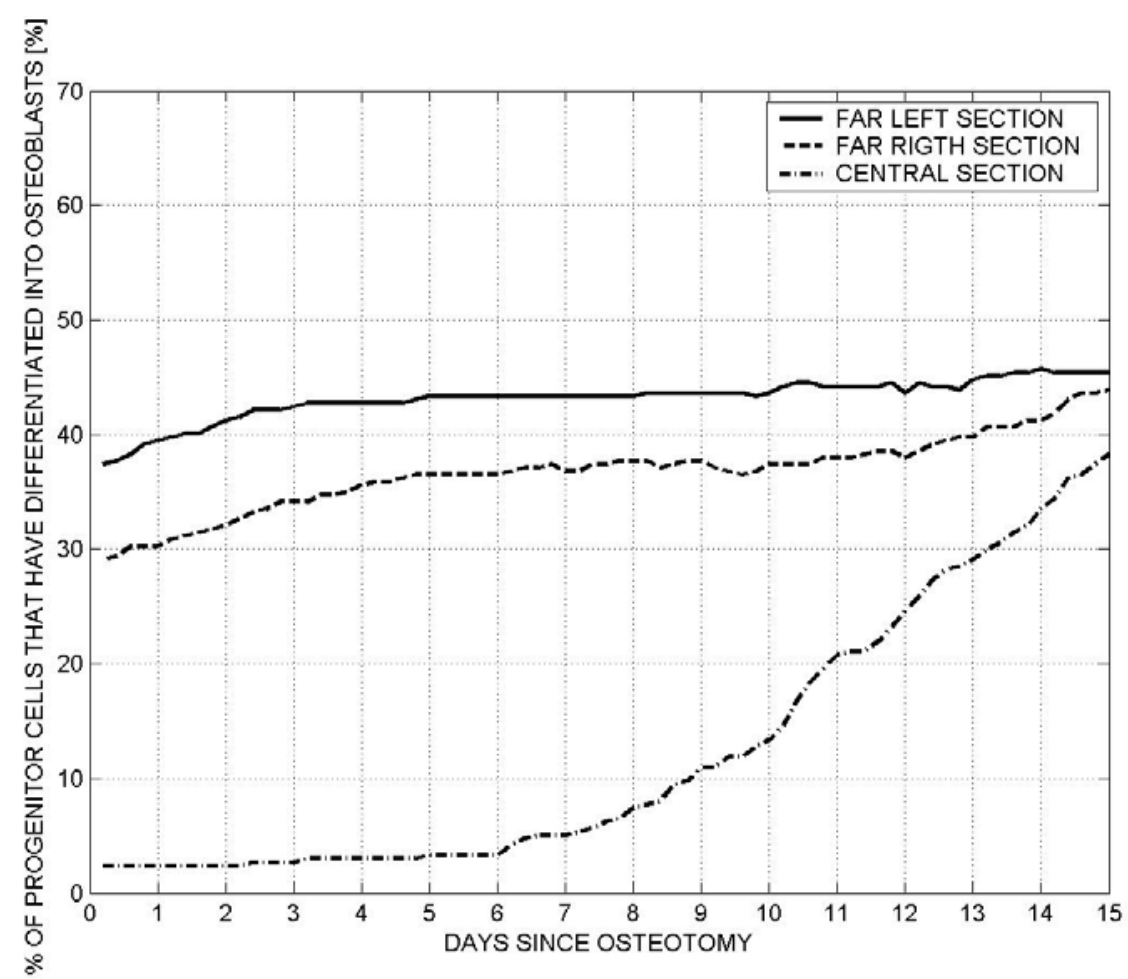

(b)

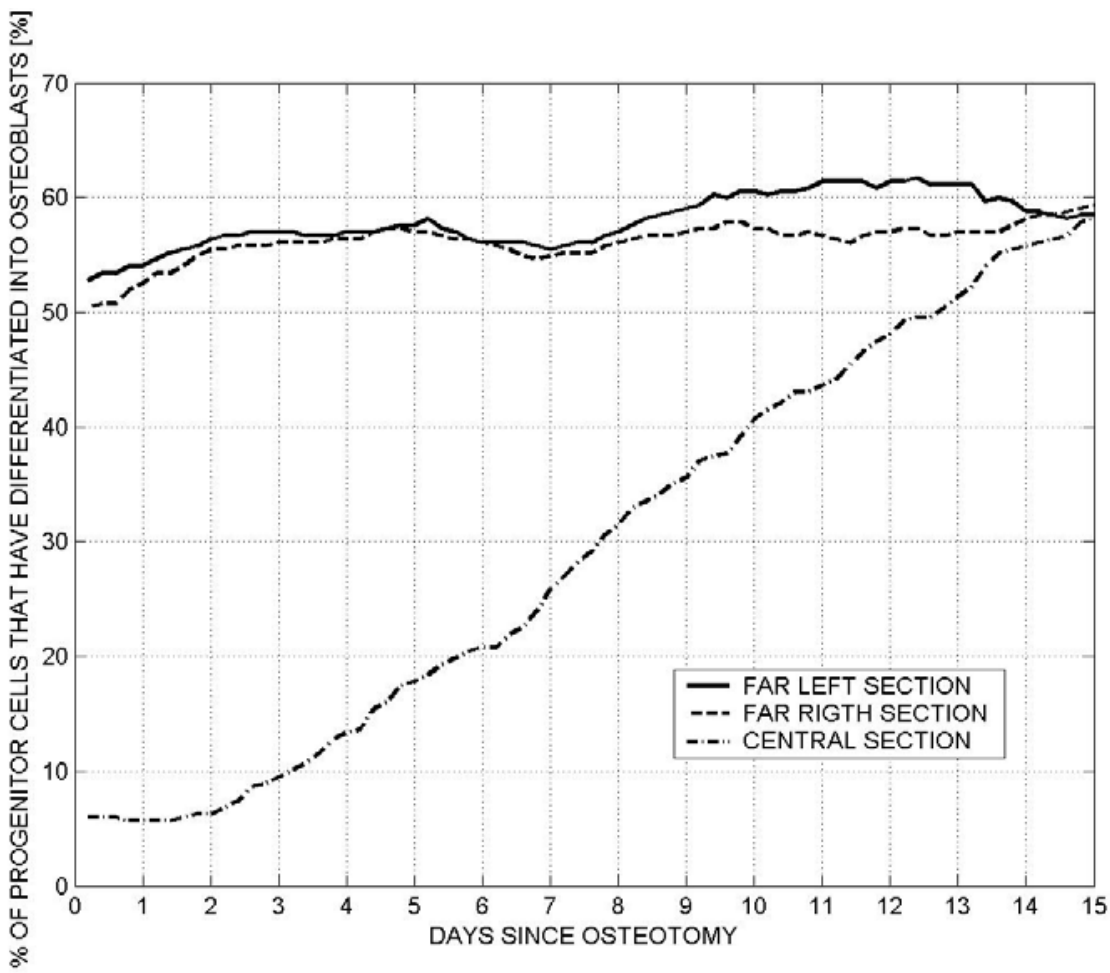

Figure 7. Bone percentage on the Far Left Section (FLS), Far Right Section (FRS) and Central Section (CS) for (a) full mastication loading and (b) for mastication loading reduced by $70 \%$. 

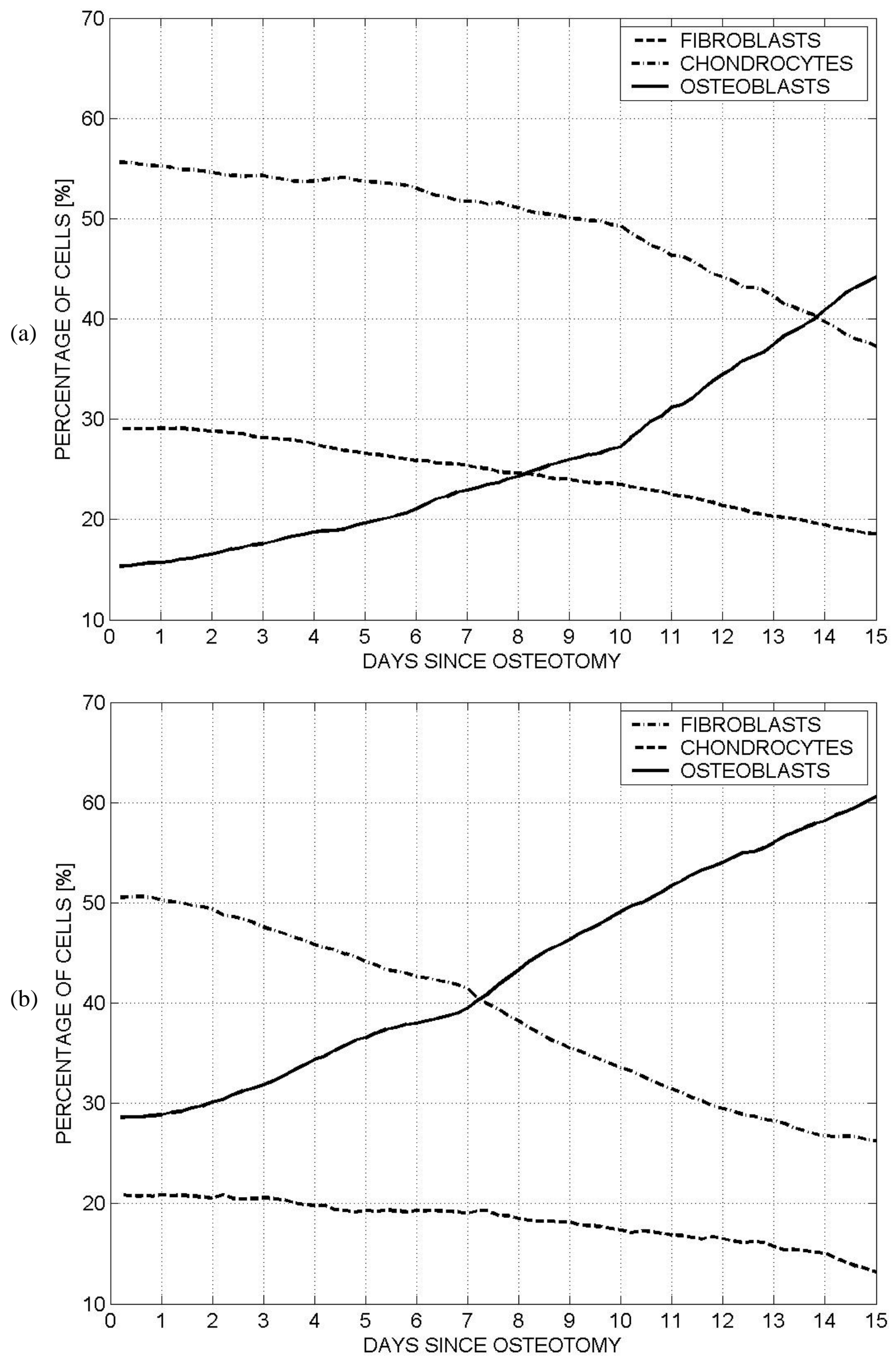

Figure 8. Percentage values of the tissues composing the bone callus. 


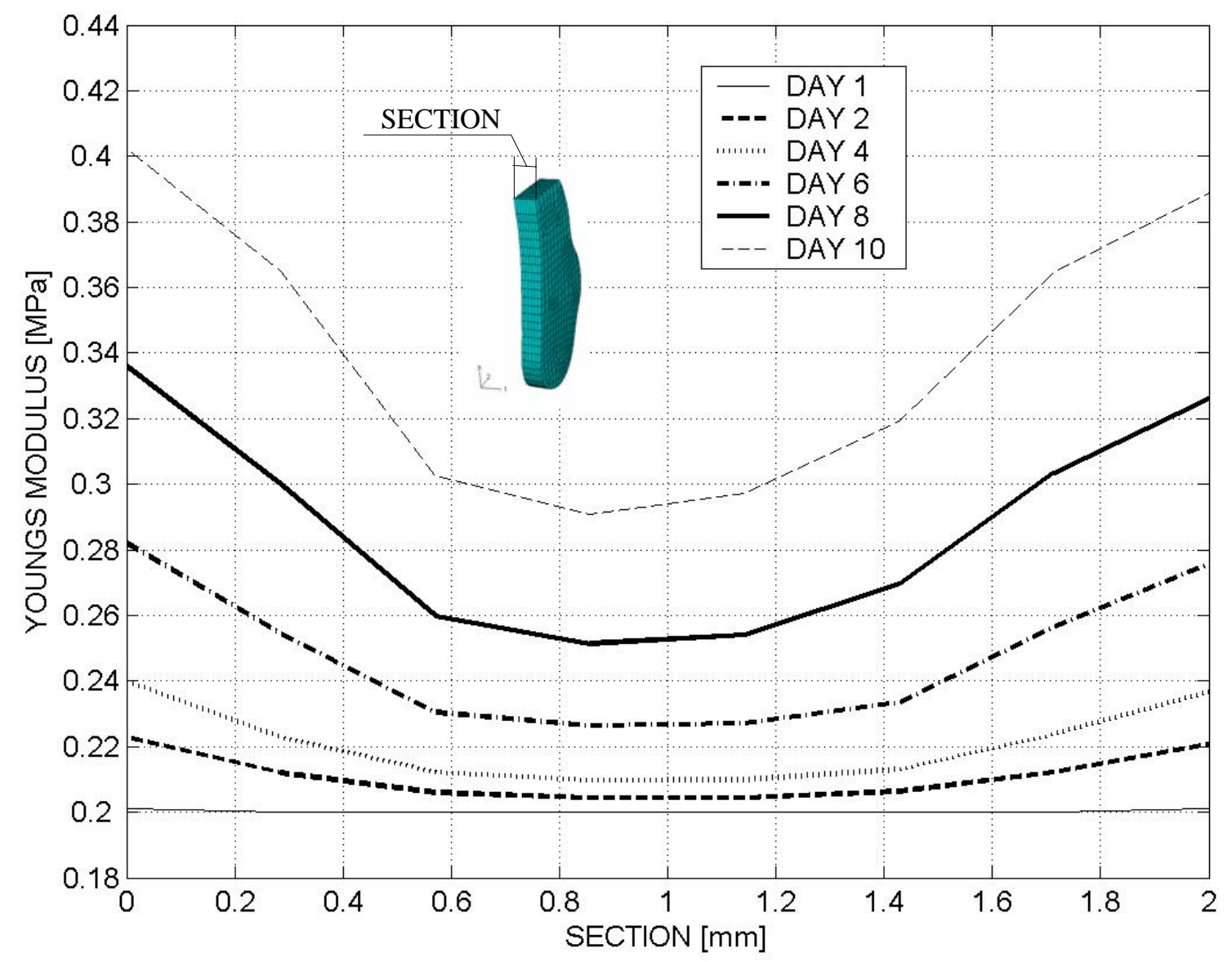

Figure 9. Mechanical properties of the bone callus at different time step. Full mastication loads are applied. 


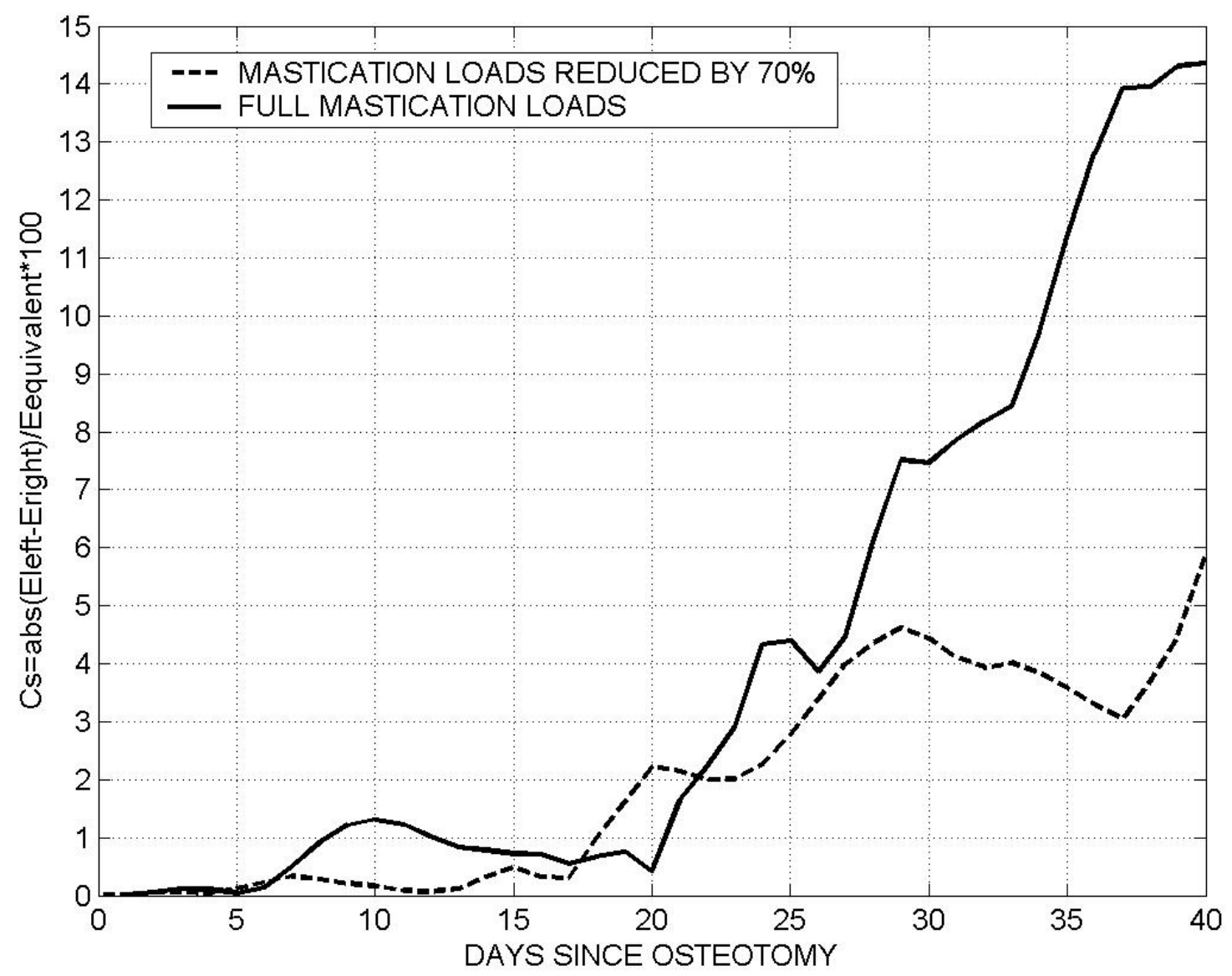

Figure 10. Symmetry coefficient $C_{S}$ at different days since the osteotomy for full mastication loads and for mastication loads reduced by $70 \%$. 
FULL MASTICATION LOAD
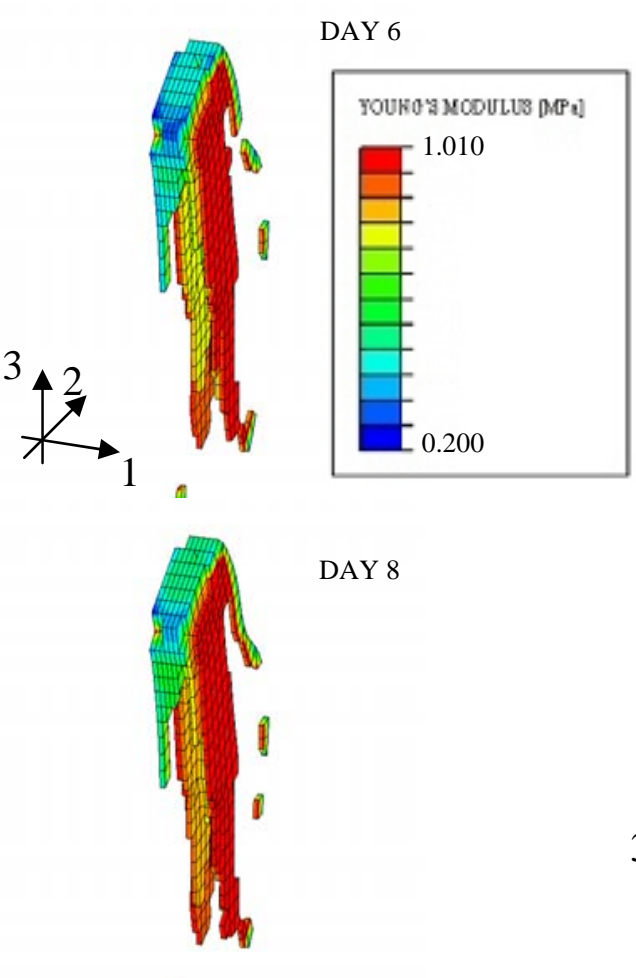

DAY 10

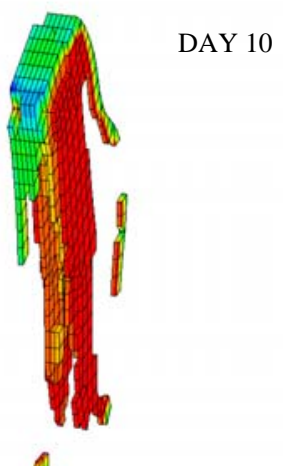

DAY 15
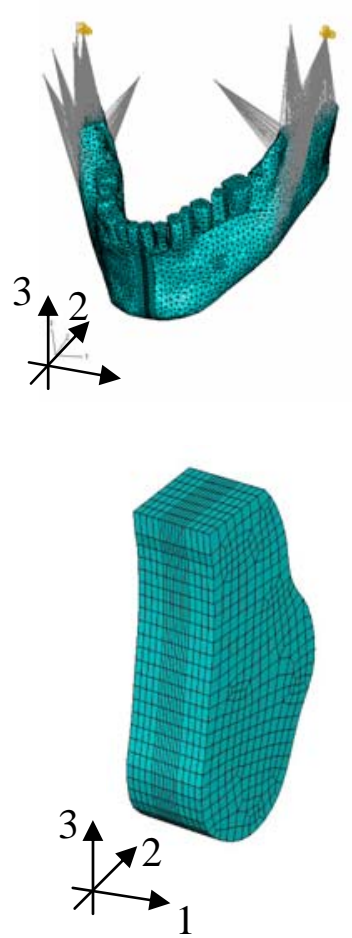

REDUCED MASTICATION LOAD

DAY 6
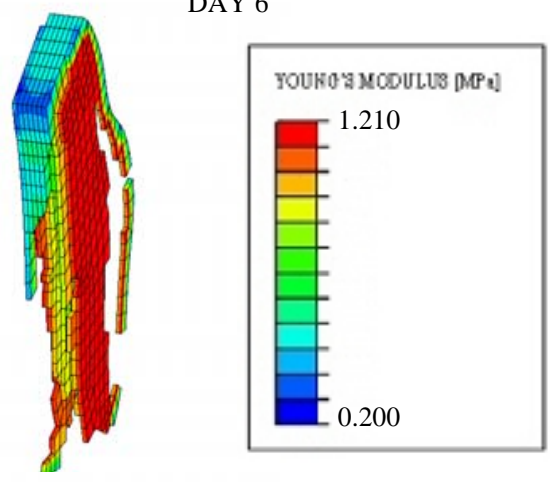

DAY 8

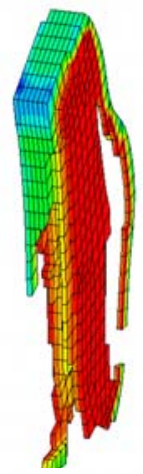

DAY 10

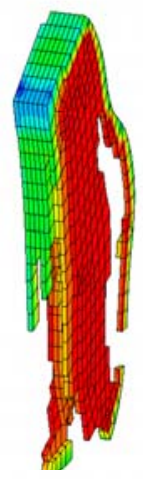

DAY 15
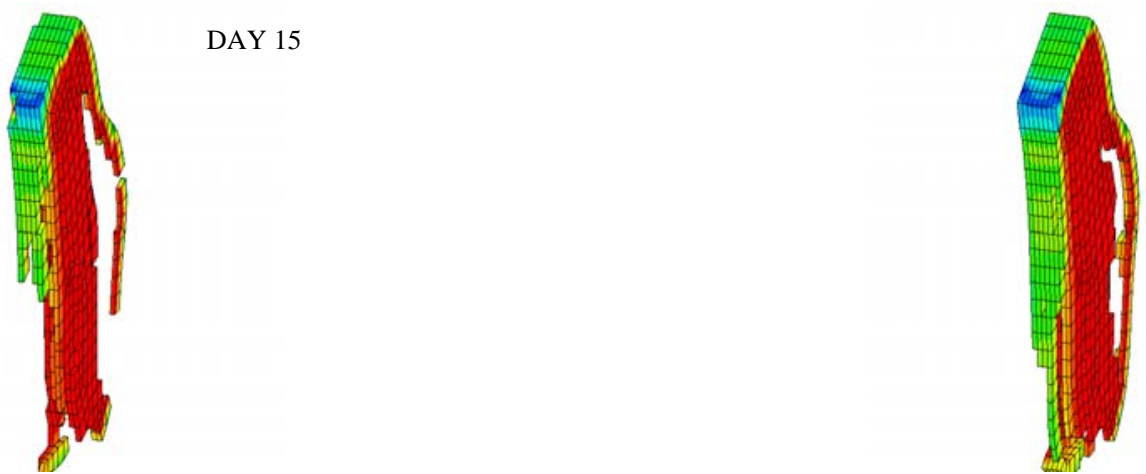

Figure 11: 3D visualization of the tissue formation within the callus. Only elements containing osteoblasts are included. LHS: full mastication loading. RHS: mastication loads reduced by $70 \%$. 

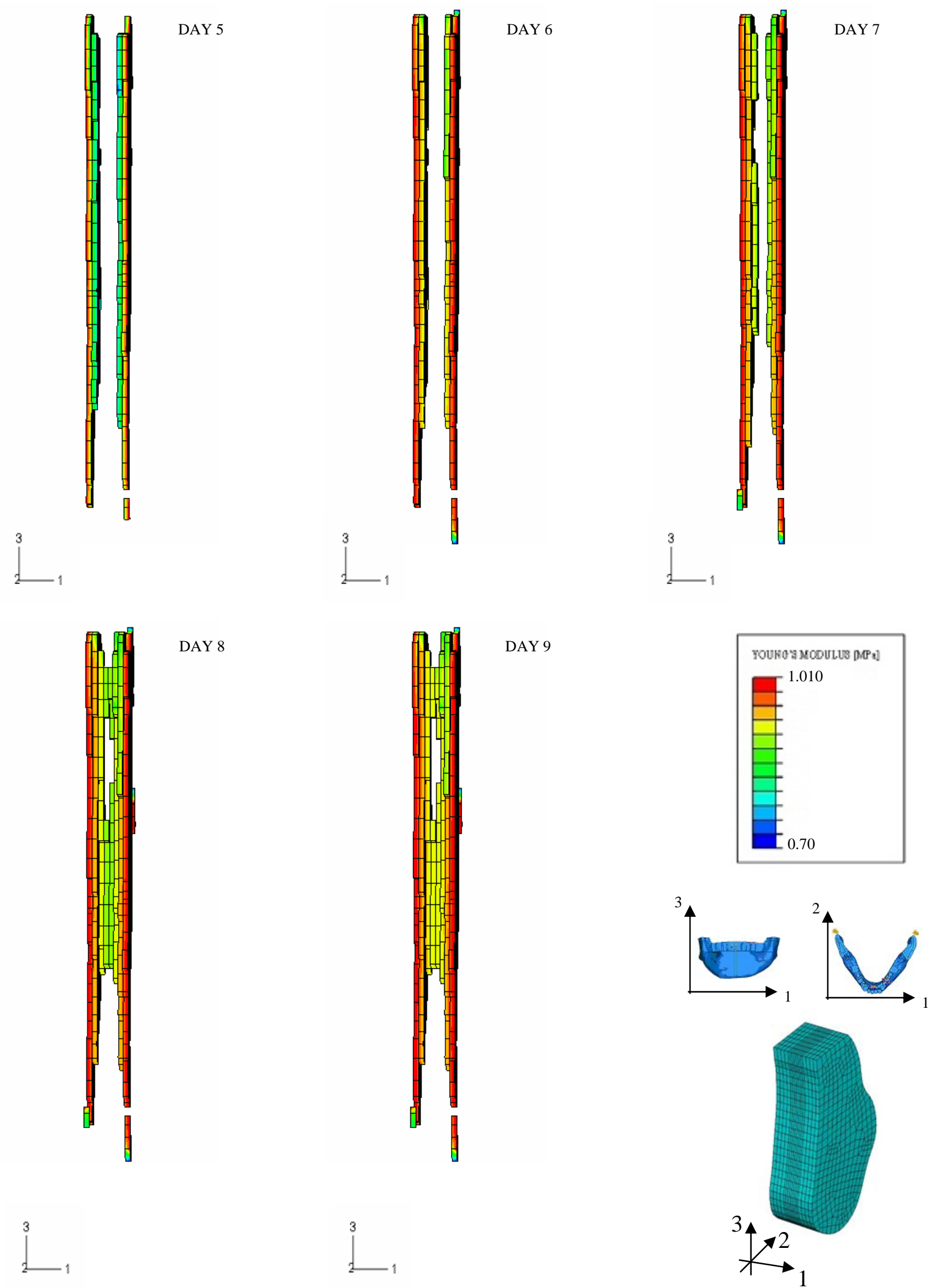

Figure 12. 3D visualization of the bone regeneration process. Full mastication loads are applied. 

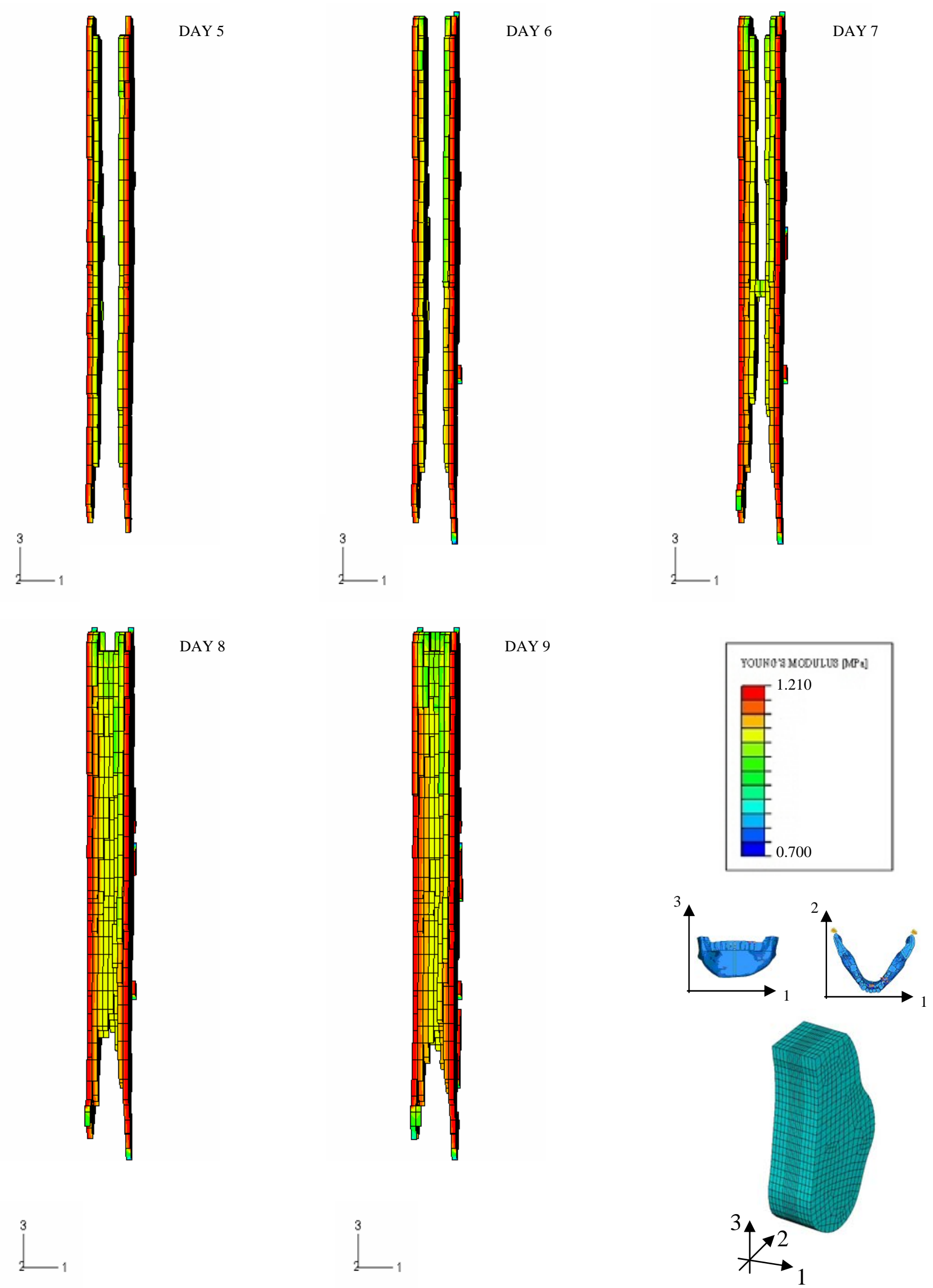

Figure 13. 3D visualization of the bone regeneration process. Mastication loads are reduced by $70 \%$. 


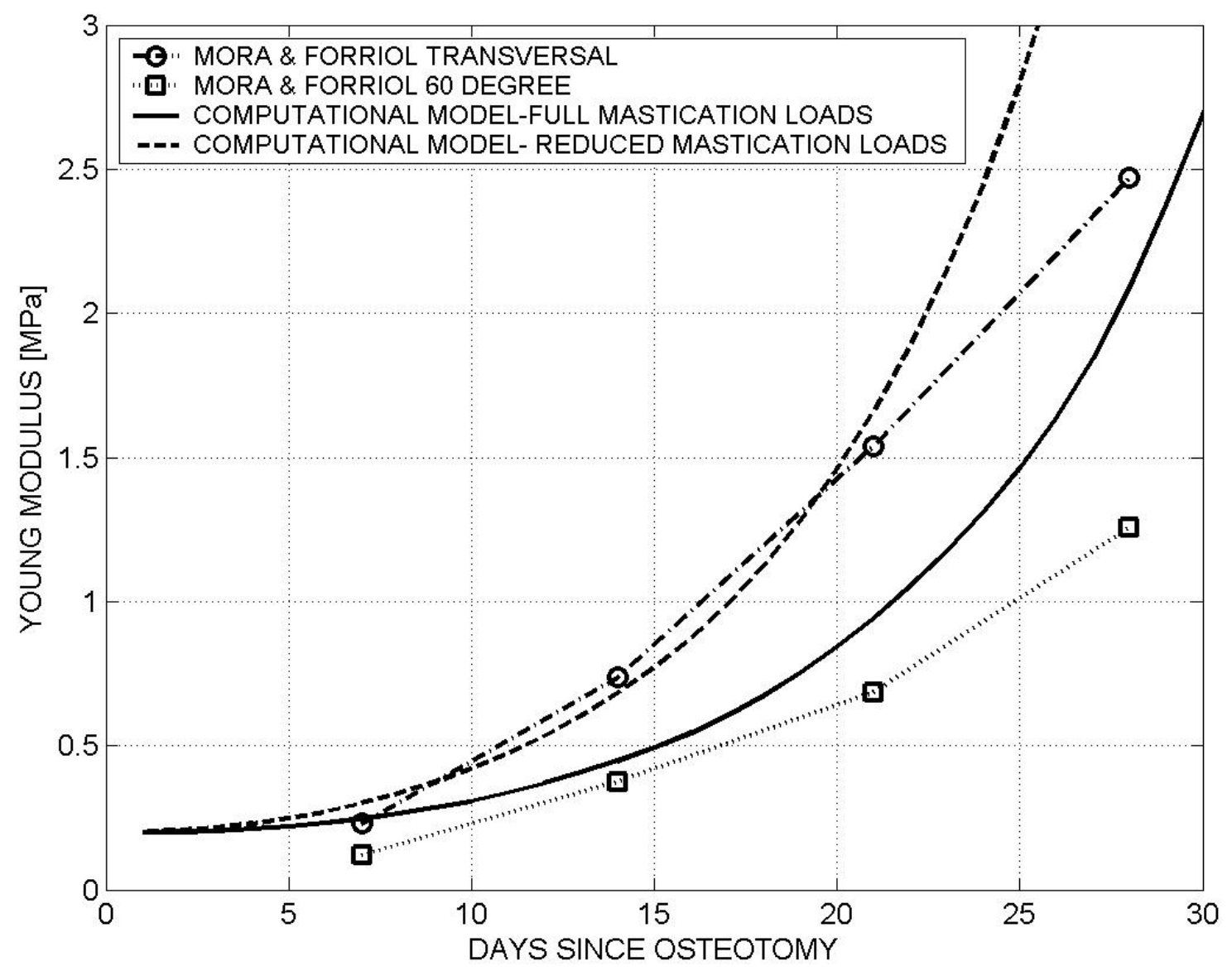

Figure 14. Comparison between the mechanical properties evaluated with the proposed model and the experimental data measured from Mora and Forriol (2000). 


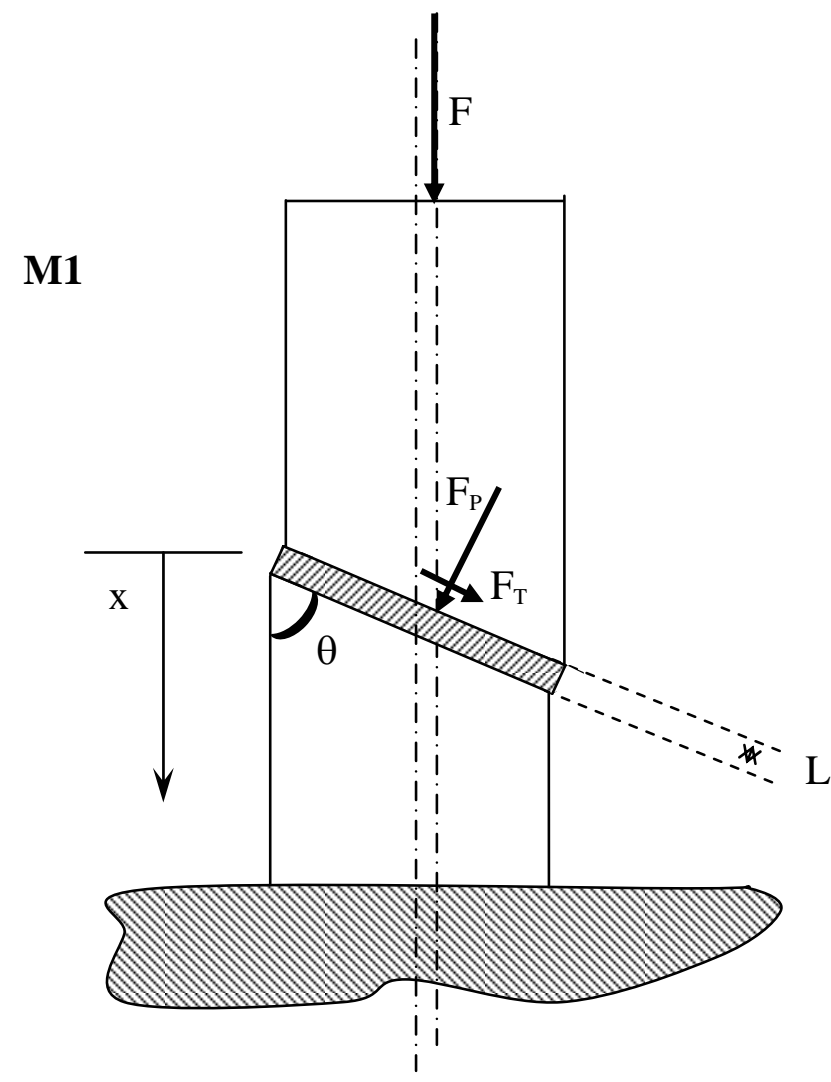

Figure B1. Estimation of the Young's modulus in an oblique bone fracture 


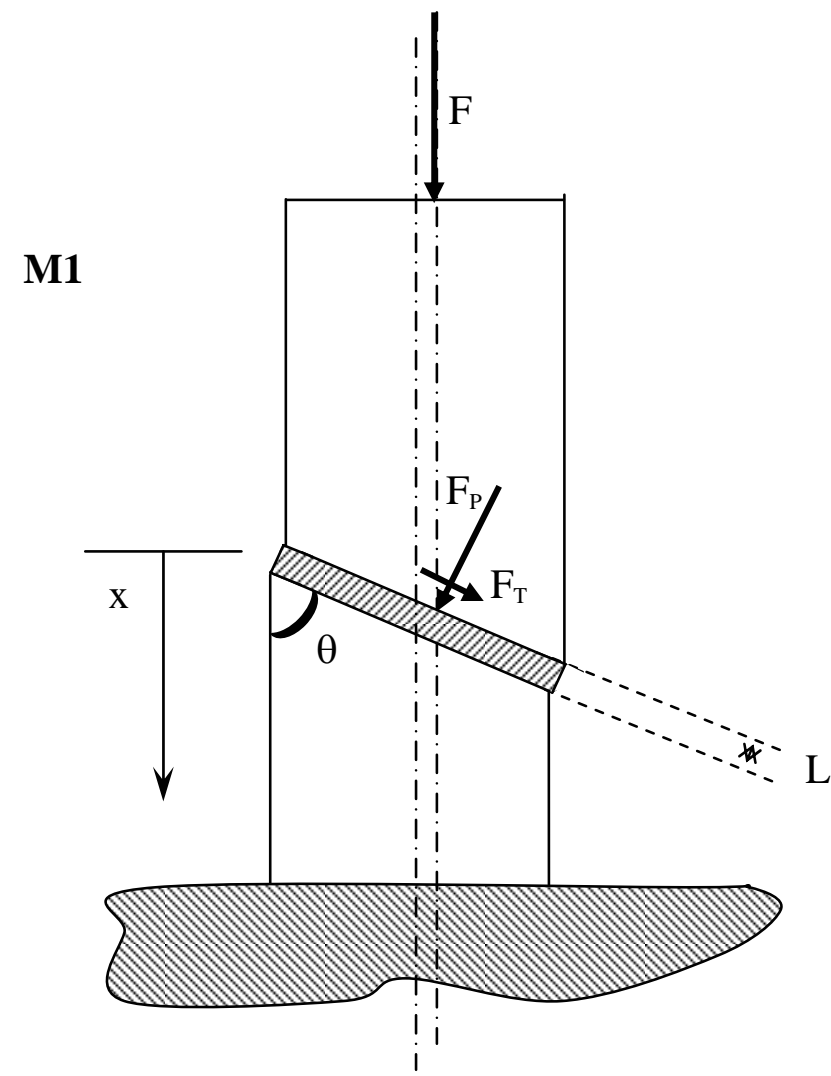

Figure B1. Estimation of the Young's modulus in an oblique bone fracture 